\title{
Advances in dietary fibre characterisation. 2. Consumption, chemistry, physiology and measurement of resistant starch; implications for health and food labelling
}

\author{
Martine Champ ${ }^{1 *}$, Anna-Maria Langkilde ${ }^{2}$, Fred Brouns ${ }^{3,4}$, Bernd Kettlitz $^{3}$ and Yves Le Bail-Collet ${ }^{3}$ \\ ${ }^{1}$ Unité Fonctions Digestives et Nutrition Humaine, INRA Nantes, Rue de la Geraudière, BP 71627, 44316, \\ Nantes Cedex 3, France \\ ${ }^{2}$ Department of Clinical Nutrition, Sahlgrenska University Hospital, Göteborg University, Sweden \\ ${ }^{3}$ Cerestar, Research and Development Centre, Havenstraat 84, B-1800 Vilvoorde, Belgium \\ ${ }^{4}$ Maastricht University, Nutrition and Toxicology Research Institute Maastricht, Maastricht, The Netherlands
}

\begin{abstract}
Resistant starch (RS) is defined as 'the sum of starch and products of starch degradation not absorbed in the small intestine of healthy individuals'. This basic definition includes different types of starches that (1) are physically inaccessible, usually due to an encapsulation in intact cell walls, or (2) are naturally highly resistant to mammalian $\alpha$-amylase, or (3) have been modified by hydrothermic treatments then retrograded. Interest in RS has increased significantly during the last two decades, mostly due to its capacity to produce a large amount of butyrate all along the colon. Butyrate has been observed to have a range of effects on cell metabolism, differentiation and cell growth as well as inhibition of a variety of factors that underlie the initiation, progression and growth of colon tumours. The physiological definition of RS, which seems to be nearly consensual, raises a difficulty in proper analytical quantification of RS. A number of methods have, however, been proposed and provide similar values for the RS content in most of the starch types and starchy foods. It seems, however, that some starches, proven to be partly resistant according to in vivo investigations on ileostomy subjects, could not be quantified by most of these methods. This may be due to a widespread use of glucoamylase during the first steps of these methods. Accordingly, there is an international debate on health aspects of RS and on how to quantify the RS content of food products. The present review describes aspects of classification of RS, past and current consumption, physiological effects and analytical aspects, and concludes with impacts on food and product labelling.
\end{abstract}

Dietary fibre: Resistant starch: Food analysis: Food labelling

\section{Introduction}

Resistant starch (RS) is present in a wide variety of carbohydrate-based foods and may constitute up to $15 \%$ of the DM of a food product. Several studies indicate that its presence in food might be beneficial for health (Asp et al. 1996). RS is by definition not absorbed in the small intestine (Asp, 1992), thus it does not contribute to postprandial hyperglycaemia (Ranganathan et al. 1994). Its effect on lipid metabolism has recently been investigated. When added to meals, RS may be beneficial for patients with subnormal or abnor- mal levels of lipaemia (Faisant et al. 1994). Moreover, some animal studies indicate a serum cholesterol-lowering effect but no evidence of similar effects in human subjects has been demonstrated (Heijnen et al. 1996). RS is largely fermented, producing short-chain fatty acids (SCFA) and bacterial cells. It may be important for colonic epithelial cell health through effects on bile acids, butyrate production and moderation of $\mathrm{N}$ metabolism (Cummings et al. 1994; Hylla et al. 1998). A number of studies of the effect of RS on bowel habit have been reported but findings are somewhat inconsistent (Cummings et al. 1994).

\footnotetext{
Abbreviations: ACF, aberrant crypt foci; AOAC, Association of Official Analytical Chemists; BA, butyric acid; EURESTA, European Flair-Concerted Action Research Programme; RS, resistant starch; RS1, physically inaccessible starch; RS2, resistant starch granules; RS3, retrograded starch; RS4, chemically modified starch; SCFA, short-chain fatty acids.

* Corresponding author: Dr Martine Champ, fax +33 2406750 12, email champ@ nantes.inra.fr
} 


\section{Classification of resistant starch}

The increasing knowledge of starch digestion in man has allowed a new classification of RS that is commonly accepted (Englyst et al. 1992, 1996a). Three classes of RS are usually described in the literature but recently a fourth class has also been identified. The four classes of RS are: physically inaccessible starch (RS1); resistant starch granules (RS2); retrograded starch (RS3); chemically modified starch (RS4).

\section{Physically inaccessible starch}

RS1 is found in partly milled grains and seeds. Legumes such as beans or lentils are known to be one of the main sources of RS1 due to the thickness of the cell walls. The preparation and cooking process is of great importance for the RS1 content of food when consumed as these procedures can contribute to a disruption of the cell walls.

\section{Resistant starch granules}

B-type starches, such as raw potato and banana starch, are known to be very resistant to enzymic hydrolysis when uncooked. B-type refers to the X-ray diffraction pattern of the starch. Raw starches are classified in three main types: A (for example, most cereal starches, cassava starch); B (for example, potato and banana starches; Englyst \& Cummings, 1986; Faisant et al. 1995a); C (most legume starches). Most cooking procedures are able to gelatinise raw starches allowing the disappearance of RS2 in the food. Accordingly, banana, which is mostly consumed raw, is the main source of RS2 in the human diet; how much RS is contained in the fruit depends on the degree of ripening as during this process the banana's intrinsic enzymes convert the starch into simple sugars and sucrose.

\section{Retrograded starch}

RS3 is present in most starchy foods, which have been cooked then cooled and stored for several hours, up to several months. Retrogradation is a recrystallisation of starch chains, which occurs after gelatinisation when the product has not been immediately dried. Single chains form double helixes. Mainly the linear fraction of the starch, the amylose, is involved; amylopectin, however, can also retrograde, although a much longer time is needed. Cooked and cooled potatoes have been shown to contain RS3 in significant amounts (Englyst \& Cummings, 1987). Reheating of starch reduces the RS3 content of the potato, showing that the retrogradation is partly reversible. Several cycles of heating and cooling, however, allow an increase in the RS3 levels.

RS1, RS2 and/or RS3 can co-exist in the same food. A meal of beans, for example, contains both RS1 and RS3 (Noah et al. 1998) whereas RS1 and RS2 are present in bananas (Faisant et al. 1995a).

\section{Chemically modified starch}

RS4 has only recently been described. It includes starch ethers and esters as well as cross-bonded starches that are resistant to small-intestinal digestion (Baghurst et al. 1996; Brown et al. 1998).

\section{History of the resistant starch concept}

It has been known for a long time that starch may escape small-intestinal digestion, as starch granules have been found in faeces of animals and human subjects. RS was originally defined as the component of starch that survives exhaustive digestion with amylolytic enzymes and was associated with raw starches with an X-ray diffraction pattern of type B (raw banana or potato starches). In animal nutrition, it was first seen as a decrease of the energy value of starchy products. However, the identification of a specific fermentation profile (rich in butyrate) of RS and the first studies on butyrate and cell proliferation and differentiation have boosted the medical and physiological interest for RS.

The laboratories of Cummings and Stephen (Stephen et al. 1983; Englyst \& Cummings, 1985) were the first to stress the quantitative importance of the undigested fraction of starch in the human diet. This became possible at the beginning of the 1980 s by studying ileostomy patients (patients without a colon) in which direct in vivo smallintestinal digestibility measurements were possible (Sandberg et al. 1981). Accordingly one could establish the true RS content of foods in vivo, without invasive techniques. Furthermore, the technique of intestinal intubation and perfusion of the small and large intestine of healthy subjects was developed. Research on digestibility has accumulated since then and the European Flair-Concerted Action Research Programme (EURESTA), which started in 1990, has undoubtedly stimulated further research on RS in Europe as well as in other parts of the world.

\section{Past and current resistant starch intake data}

Daily RS intake apparently increased in Australia between 1988 and 1993 (Baghurst et al. 1996); from 4.93 to $5.33 \mathrm{~g}$ in the male population and from 4.37 to $4.96 \mathrm{~g}$ intake in the female. Expressed in $\mathrm{g} / 10 \mathrm{MJ}$ of total energy intake, the consumption of RS was higher for females than for males, 6.26 and $5.43 \mathrm{~g} / 10 \mathrm{MJ}$, respectively, in 1993 . There is no clear evolution of RS consumption with age (over 18 years of age) when correlated to energy intake. However, in 1993, males over 60 years had the highest RS consumption (5.76 g RS/10 MJ) among the male population. In females, the highest consumption was observed in the group aged $50-59$ years $(6 \cdot 57 \mathrm{~g} / 10 \mathrm{MJ})$. The contribution of main foods to total RS intake had been analysed in the CSIRO National (Australia) Survey of Adults in 1993. Three groups of foods contributed more than $73 \%$ of the total RS intake: bread and crackers $(24.7 \%)$, vegetables $(26.1 \%)$ and, surprisingly, fruits and fruit juices $(22 \cdot 3 \%)$ (Table 1$)$. According to the CSIRO survey, in Australia, RS intake varied from $0 \cdot 12$ to $17 \cdot 30 \mathrm{~g}$ with a 5 th and 95 th percentile of 2.3 and $8.8 \mathrm{~g}$ (Baghurst et al. 1996). However, these values are considered as being underestimated as the RS databases are only related to RS3.

The National Dietary Survey of Schoolchildren (1985) and Adults (1983) (Baghurst et al. 1996) from the Commonwealth Department of Health revealed that the RS intake of Australian children (both boys and girls) did not differ from that of adults (Table 2). 
Table 1. Estimated food sources of resistant starch from CSIRO National (Australia) Survey of Adults, 1993 (from Baghurst et al. 1996)*

\begin{tabular}{lcc}
\hline & \multicolumn{2}{c}{ Contribution to total intake } \\
\cline { 2 - 3 } Food source & $1988(\%)$ & $1993(\%)$ \\
\hline Bread and crackers & 26.9 & 24.7 \\
Vegetables & 26.6 & 26.1 \\
Fruit and fruit juice & 21.8 & 22.3 \\
Rice and pasta & 8.7 & 11.6 \\
Breakfast cereals & 4.8 & 5.7 \\
Takeaways and snacks & 4.2 & 3.6 \\
Processed meats and meat dishes & 3.8 & 2.6 \\
Confectionery, cakes and biscuits & 2.1 & 2.2 \\
Dairy and ice cream & 0.5 & 0.5 \\
Chicken, fish and eggs & 0.4 & 0.4 \\
Drinks & 0.1 & 0.0 \\
Spreads and sauces & 0.0 & 0.3 \\
Red and organ meat & 0.0 & 0.0 \\
\hline
\end{tabular}

* Most available resistant starch databases relate to retrograded starch only (RS3). Population intakes will be higher if other forms are included at a later date.

Estimates of RS consumption in Western developed countries vary widely in the literature, with values ranging from 3-4 to 15-20 g/d. Estimates for developing countries range from 9-10 to $30-40 \mathrm{~g} / \mathrm{d}$ for countries with high starch intakes (Stephen et al. 1995). According to the EURESTA evaluation of RS intake in Europe (Dysseler \& Hoffem, 1994a), values range from 3.5 to $6.0 \mathrm{~g} / \mathrm{d}$ in the European countries. Baghurst et al. (1996) estimated that the RS intake represents $5 \%$ of the overall starch consumption.

The recent report on the assessment of RS consumption in France (AD Brousseau, A Dufour and JL Volatier, unpublished results) indicated an average daily consumption of $4 \cdot 2$ g RS with 1.9 and $7.4 \mathrm{~g}$ for the 5 th and the 95 th percentiles. Generally it appears that the main categories of foods that determine the daily RS intake are cereal-based products (mainly bread, pasta and rice) and vegetables (legumes and potatoes; Table 3). In Italy, the average intake of RS has been estimated by Brighenti et al. (1998) to be $8.5 \mathrm{~g} / \mathrm{d}$, with regional differences (from $7 \cdot 2$ in the North-West to $9 \cdot 2 \mathrm{~g} / \mathrm{d}$ in the South) mainly due to the different consumption of some typical starchy foods (bread, pasta and legumes).

\section{Epidemiological data}

A strong inverse correlation between colon cancer and starch intake was shown by Cassidy et al. (1994). No link was seen between NSP intake and colon cancer whereas an inverse relationship was found between colon cancer and the sum NSP + RS, assuming $5 \%$ of all starch consumed to be resistant.

This epidemiological association of decreased colon cancer risks with high per capita starch intakes, if causal, may be due to the colonic fermentation of the RS fraction resulting in significant butyrate production. To our knowledge there is at least one ongoing intervention study on RS, the so-called CAPP study. It first started in Newcastle upon Tyne (UK) on adolescents with familial adenomatous polyposis who since 1993 have been given $600 \mathrm{mg}$ aspirin and/or $30 \mathrm{~g}$ RS sources or placebo (CAPP1; Burn et al. 1995). This study has now been extended to forty-six centres worldwide (CAPP 2; Burn et al. 1998). The RS source is a mixture of Hylon 7 (native high-amylose $(70 \%$, w/w) maize starch from National Starch) and potato starch $(50: 50, w / w)$. No results have yet been released.

\section{Experimental data}

There is a number of studies on animal models and human subjects on the possible digestive and metabolic effects of RS. Until now, most of the experimental data are obtained from short-term intervention studies. It is impossible to mention all these data in the present paper and only the main results will be summarised (see pp. 145-147).

\section{Resistant starch, blood glucose, insulin and diabetes}

Because RS is not digested in the small intestine it does not contribute to the postprandial glucose response. The question has been raised whether RS could influence the digestion of the digestible starch and the absorption and/or metabolism of the glucose resulting from its digestion. It has been shown that there is no alteration of postprandial glucose response when RS is added to a meal (Ranganathan et al. 1994).

On a long-term basis, there is no strong evidence available that a high RS content (per se) in foods may be of significant benefit to diabetics or a non-diabetic population (Baghurst et al. 1996).

\section{Resistant starch, gut disorders and colon cancer}

RS does not seem to change bowel transit time in human subjects (Flourié et al. 1986; Shetty \& Kurparch, 1986; Scheppach et al. 1988; Tomlin \& Read, 1990; Van Munster et al. 1994) whereas some starches (RS2 and RS3, according to Heijnen et al. (1998) and Hylla et al. (1998))

Table 2. Mean daily intakes of resistant starch (RS) from Commonwealth Department of Health, National (Australia) Dietary Surveys of Schoolchildren (1985) and Adults (1983) (from Baghurst et al. 1996) (Minimal and maximal values)

\begin{tabular}{|c|c|c|c|c|}
\hline & \multicolumn{2}{|c|}{ Age $10-15$ years } & \multicolumn{2}{|c|}{ Age $25-64$ years } \\
\hline & Boys & Girls & Men & Women \\
\hline$R S(g / d)$ & $4 \cdot 0-5 \cdot 6$ & $3 \cdot 4-3 \cdot 7$ & $4 \cdot 0-5 \cdot 2$ & $2 \cdot 7-3 \cdot 2$ \\
\hline$R S(g / 10 \mathrm{MJ} \text { per } d)^{*}$ & $4 \cdot 7-5 \cdot 0$ & $4.5-4.9$ & $4 \cdot 1-4 \cdot 4$ & $3 \cdot 9-4 \cdot 3$ \\
\hline
\end{tabular}

${ }^{*} \mathrm{~g} / 10 \mathrm{MJ}$ of total energy intake. 
Table 3. Estimation of resistant starch intake $(\mathrm{g} / \mathrm{d})$ in the general French population (AD Brousseau, A Dufour and JL Volatier, unpublished results) (Mean values and standard deviations)

\begin{tabular}{lllll}
\hline Categories of foods & Mean & SD & 5th percentile & 95th percentile \\
\hline Cereal-based products & 2.032 & 1.137 & 0.638 & 3.843 \\
Desserts and biscuits & 0.371 & 0.386 & 0 & 1.038 \\
Vegetables & 1.474 & 1.009 & 0.213 & 3.271 \\
Prepared dishes & 0.212 & 0.327 & 0 & 0.910 \\
Fruits & 0.144 & 0.269 & 0 & 0.626 \\
\hline
\end{tabular}

increase stool weight and hydration of colonic content by an increase of the bacterial mass and fermentation.

It is apparent that most $\mathrm{RS}$ are readily fermentable, as they are known to be good sources of butyric acid (BA) production in the colon. Indeed data in Table 4 demonstrate clearly that butyrate production from RS is among the highest of individual fibres tested (Kritchevsky, 1995). There is abundant evidence from animal and cell-line studies on the preventive effects of butyrate on colon cancer and adenoma development (Blottière et al. 1999). Butyrate has been observed to induce gene expression as well as to influence the rate of gene expression through its effects on transcription (Kruh et al. 1995). Key modifications are nuclear histone acetylation and phosphorylation, which affect the cell chromatin structure as well as modifications of hormone receptor binding. Additionally $\mathrm{BA}$ has been observed to induce apoptosis and as such to reverse the resistance of colonic cancer cells to programme cell death (Chapkin et al. 2000). However, a mediating effect of BA production to explain the association of lowered risks of colon cancer with high dietary fibre intakes in human subjects still requires confirmation. The half-life time of $\mathrm{BA}$ is very short and as such any effect of BA on the colon can only be expected in cases where there is a consistent production over a large segment of the colon. Moreover, the specific effect of substrates that produce significant amounts of butyrate can only be confirmed in intervention studies on healthy populations and 'at risk' populations that are linked to a genetic predisposition or earlier resection of polyps. However, the compelling evidence from animal intervention studies is highly promising even if some of them do not show a beneficial effect of butyrate-producing substrates.

There is now a large number of papers on the impact of the consumption of substrates that generate high amounts

Table 4. Patterns of short-chain fatty acids production from various substrates (from Kritchevsky, 1995))

\begin{tabular}{llll}
\hline & \multicolumn{3}{c}{ Percentages of total acids } \\
\cline { 2 - 4 } Substrates & Acetate & Propionate & Butyrate \\
\hline Resistant starch & 41 & 21 & 38 \\
Starch & 50 & 22 & 29 \\
Oat bran & 57 & 21 & 23 \\
Wheat bran & 57 & 15 & 19 \\
Cellulose & 61 & 20 & 19 \\
Guar gum & 59 & 26 & 11 \\
Ispaghula & 56 & 26 & 10 \\
Pectin & 75 & 14 & 9 \\
\hline
\end{tabular}

of butyrate (wheat bran, inulin, fructo-oligosaccharides, and RS) in the colon. In most cases, the animal models have been rats with chemically induced cancer (by dimethylhydrazine or azoxymethane). The authors examined tumour development or aberrant crypt foci (ACF). For example, McIntyre et al. (1993) concluded from their study on wheat bran $(10 \%(\mathrm{w} / \mathrm{w})$ of the diet) and dimethylhydrazine-treated rats that fibres that are associated with high butyrate concentrations in the distal large bowel are protective against large-bowel cancer. Rowland et al. (1998) observed a decrease (41\%) in azoxymethane-induced small $\mathrm{ACF}$ when rats were fed inulin $(5 \%, \mathrm{w} / \mathrm{w})$ in their diet. They concluded that inulin was associated with beneficial changes in caecal physiology and bacterial metabolic activity in relation to tumour risk and in the incidence of putative pre-neoplastic lesions.

The study of Pierre et al. (1997) demonstrated on Min mice (heterozygous for a non-sense mutation in the APC gene and a good model for familial adenomatous polyposis and sporadic colon cancers) that short-chain fructooligosaccharides dramatically reduced the incidence of colon tumours and concomitantly developed gut-associated lymphoid tissue. Neither a starch-free bran nor an RS (retrograded high-amylose maize starch; RS3) modified the number of tumours. However, Perrin et al. (2001) observed in rats receiving azoxymethane that the same RS lowered potentially precocious lesions (ACF) but had no effect on the later stages of carcinogenesis. Furthermore, it was observed that only fibres promoting a stable butyrateproducing colonic ecosystem decrease the rate of $\mathrm{ACF}$ (Perrin et al. 2001).

Sakamoto et al. (1996) also investigated the effect of RS (raw potato starch; RS2) compared with cellulose on dimethylhydrazine-induced colonic carcinogenesis in rats. $\mathrm{RS}$ ( 3 and $10 \% \mathrm{RS}$ in the diet) was found to increase butyrate concentration but did not inhibit colonic carcinogenesis. They concluded that it remains an open question whether butyrate inhibits the proliferation of colon cancer. Young et al. (1996) observed more tumours and larger tumours in dimethylhydrazine-treated rats fed potato starch (RS2) (20\% of the carbohydrate content of the diet) than animals fed the basal diet. It was concluded that this RS2 enhances epithelial proliferation, ACF density, and tumour formation. Wheat bran was found to suppress tumorigenesis when added to an RS2 (10\% of the carbohydrate)-containing diet, acting on events responsible for the formation of ACF but not the events controlling the hyperproliferative phase. However, the study published by Thorup et al. (1995) with azoxymethane-treated rats found a significant 
inhibitory effect of potato starch on the development of $\mathrm{ACF}$ (but the potato starch introduced in the diet was very large; $67 \%$ ).

In vitro studies show that butyrate increases the immunogenicity of colon cancer cells and prevents the growth of cancer lines. Indeed, studies on colon cancer cell lines have shown that butyrate salts are anti-proliferative and enhance cell differentiation (Kruh, 1982; Whitehead et al. 1986) and that butyrate stimulates the immunogenicity of the cells.

Thus, the literature provides contradictory results on RS effects on colon carcinogenesis. Until now, most of the in vivo studies, on animal models, have been performed with potato starch (RS2), which is not significantly eaten by human consumers. It has become obvious that more studies should be performed on other RS sources, especially RS3 starches, since their occurrence is most abundant in the diet. Moreover, several animal models (representing different stages of the carcinogenesis process) should be used in parallel. The final and best evidence will be provided by intervention studies with RS (which will have to be properly characterised) on human populations that are at risk for colon cancer.

A reduction in cytotoxic secondary bile acids (particularly deoxycholic acid) in individuals on high-RS diets (45 g uncooked amylomaize starch/d) was shown by van Munster et al. (1994). They postulated that this could result in decreased colonic mucosal proliferation mediated through acidification of the large bowel due to the production of SCFA. A $25 \%$ increase in faecal bulk was noted on the high RS diet. Phillips et al. (1995), using a randomised crossover design, showed marked positive effects on a number of faecal parameters including faecal output, stool consistency and faecal $\mathrm{pH}$. However, the level of starch in the diet was about $40 \mathrm{~g} / \mathrm{d}$ during the high RS period compared with $5 \mathrm{~g} / \mathrm{d}$ in the low RS period. Obviously the highest RS levels will never be achieved in current patterns of food consumption.

The excretion of bile acids and cholesterol from the small intestine of ileostomy subjects has been measured in two studies. When digestible starch was replaced by retrograded high-amylose starch, bile acid excretion was found to decrease (Langkilde et al. 1998) and when cooked greenbanana flour was replaced by raw green-banana flour no change in total bile acid excretion was found (Langkilde et al. 2002).

There is some evidence that fermentable polysaccharides may also protect against potentially harmful products of protein metabolism. In the case of RS, the study of Phillips et al. (1995) showed that high RS consumption could contribute to lower faecal $\mathrm{NH}_{3}$. Additionally, a study by Heijnen et al. (1997) suggested that in particular RS3 lowers faecal $\mathrm{NH}_{3}$, while $\mathrm{RS} 2$ was ineffective.

This observation points to the possibility that not all RS have equivalent metabolic and physiological properties. It has recently also been shown in pigs, in vivo, that the uptake of butyrate by the colonic mucosa from a retrograded high-amylose maize starch (RS3) could be more efficient than from a raw potato starch (RS2) (Martin et al. 2000). From a human consumption point of view all metabolic and physiological studies carried out with raw starch sources, such as from potato, should be interpreted with care since these starch sources generally are not eaten by human consumers.

\section{Resistant starch and lipid metabolism}

RS does not lower fasting serum lipid concentrations in healthy normolipidaemic subjects (Heijnen et al. 1996; Achour et al. 1997). The first results of Faisant et al. (1994) (EURESTA) indicated that the supplementation of a normal meal with RS had little or no effect on postprandial blood parameters of normal subjects. However, triacylglycerol metabolism improved, especially in subjects with higher (upper limit of the 'normal' range) basal triacylglycerol levels, most probably by an improvement in clearance of postprandial chylomicron remnants.

When substituted for digestible starch (pregelatinised maize starch), RS3 (retrograded high-amylose maize starch) leads to a reduction in lipolysis in the post-absorptive period while blood fatty acids remain unchanged (Achour et al. 1997).

Livesey et al. (1995) have shown in ileostomy subjects that the amount of fat excretion in the ileal effluents was increased by diets that are high in RS. In two other studies in ileostomates the replacement of digestible starch by RS2 or RS3 did not alter the excretion of fat or N (Langkilde et al. 1998, 2002).

\section{Resistant starch, weight control and energy value}

The emergence of the concept of RS has opened up other possibilities in relation to dietary interventions to modify energy balance. The substitution of digestible starch or any other digestible nutrient by RS should reduce the energy value of the food, as SCFA are the only energetic nutrients that are produced during colonic fermentation. The energetic value of these SCFA is about half the energetic value of digestible carbohydrate (such as glucose). Livesey (1994) has indicated that the energy value of RS could be estimated to be about $8 \cdot 0-8 \cdot 8 \mathrm{~kJ} / \mathrm{g}$. Consequently the energetic contribution of a meal that is high in $\mathrm{RS}$ is lower than from a meal that is low in RS.

Compared with digestible starch, RS reduces subjective satiety ratings in the immediate absorptive period (Raben et al. 1994; Achour et al. 1997) but leads to higher subjective scores of satiety in the post-absorptive period (Achour et al. 1997), which may reduce subsequent food intake during the next meal. It is suggested that the fermentation product of $\mathrm{RS}$, mainly acetate, may mediate this delayed change in satiety.

\section{Relevance of distinguishing between 'isolated' and 'naturally occurring' resistant starch}

It can be questioned, as it has been earlier for dietary fibre, whether the potential beneficial effects of RS are similar when being intrinsically present in the food or when being added to the food. In the case of dietary fibre, most of the recommendations are to increase fibre-rich foods such as vegetables, fruits and wholegrain cereals in the daily diet. Isolated fibre is not always as efficient as 'naturally occurring' dietary fibre. The main reason for this difference, 
between 'isolated' and 'naturally occurring' fibres, is because most fibre is part of the cell walls. These cell walls have a complex structure in which some polysaccharides are associated, as well as non-carbohydrate substances such as vitamins, minerals, fatty acids, amino acids and other bioactive compounds such as tannins, saponins or phospholipids. The combination of these components may be more efficient than isolated fibre alone, from which such substances have been lost.

Generally speaking, this issue is quite different for RS with the exception of RS1 (physically inaccessible starch or 'trapped starch' present in pulses and whole or partly milled cereal grains), which has not been specifically studied for its physiological effects. There is no evidence that RS2 (RS granules) or RS3 (retrograded starch) behave differently if they are naturally present in the food or added to the food. It should only be kept in mind (1) that the content of RS can be influenced significantly by most of the technological treatments (more than in the case of dietary fibre) applied in common food-preparation processes and (2) that the characteristics of RS as eaten should be considered, both in cases of 'isolated and added' or 'naturally occurring' RS.

From the previous discussions it can be concluded that $\mathrm{RS}$ as a category concerns several types of starch that are resistant to digestion in the small intestine. When studied during short-term consumption as a substitute for rapidly digestible starch or as a fat replacer, they have been shown to be either beneficial or neutral with regard to most metabolic parameters. RS, when compared with other types of dietary fibre, exhibits a fermentation profile with a relatively high yield of butyrate, which, a priori, is beneficial for colonic health. Because some contradictory results have been described in the literature on the metabolic effects of different classes of RS, it is at present still difficult to draw conclusions on possible beneficial effects that may result from RS1, RS2, RS3 or RS4. Yet, a quantification of the level of RS in the daily diet would provide consumers with information that is assumed to be relevant with regard to health maintenance.

\section{Analysis of resistant starch in foods}

The growing interest in RS has led to the need for a valid analytical method for an appropriate quantification of RS in food and food products. RS has been defined as 'the sum of starch and products of starch degradation that are not absorbed in the small intestine of healthy individuals' (Asp, 1992). Thus, according to this definition the analytical method of choice to quantify the RS content of foods should measure all the starch and $\alpha$-dextrins present. Furthermore, this analytical method should be validated by a direct comparison of the data obtained in vitro with the true in vivo data from healthy subjects.

A physiological definition of RS is probably most intellectually satisfying but seems to be particularly difficult for several reasons. First of all, differences between digestible starch and RS are those that are related to the structural organisation of the starch and/or to the functional and physiological environment during the process of digestion. These factors are known to affect the digestive enzyme accessibility to the RS substrate. Starch digestion in itself is also dependent on the efficacy of chewing, the gastrointestinal transit time and the quantitative enzyme secretion. All these factors may vary from one subject to the other. However, from an analytical point of view there are no differences between digestible starch and RS.

Therefore, the in vitro method of choice has to provide results that are similar to the average response of a population of healthy individuals. Preferably a validation of the in vitro method should be done with a large range of $\mathrm{RS}$ sources on a sufficiently large number of subjects.

Another difficulty is the choice of an appropriate method to obtain reliable in vivo RS values. Two methods are currently available: (1) intestinal intubation of healthy subjects to collect the residual starch at the end of the ileum; (2) the ileostomy model using subjects with a large-bowel resection but an intact and healthy small bowel. Both techniques have been subject to some criticism. The advantages and disadvantages of each of these techniques will be discussed later (pp. 148-149 and 151-154).

\section{Current in vitro methods}

During the last decade much effort has been put into the evaluation and subsequent improvement of the existing methods for the measurement of RS. A review presenting most of these methods in detail has been published recently (Champ et al. 1999a). Several analytical methods are now being put forward in the literature as being most appropriate. Some of these were developed during the European Research Programme EURESTA (Champ, 1992; Englyst et al. 1992). When direct comparisons were made, the different methods seemed to provide very similar data for most starch samples tested. However, most of these methods appear to underestimate the RS as it has been defined in 1992 by Asp. Indeed, RS collected in vivo in human subjects (ileostomates or intubated healthy subjects) is composed of oligosaccharides (including glucose), $\alpha$-glucans of high molecular weight (mainly starch granules) and a crystalline fraction, the size of which depends on the origin and the treatment of the starch. None of the analytical methods for RS takes into account the potentially digestible starch (oligosaccharides and part of the high-molecular-weight fraction) (Faisant 1993a,b).

\section{Main analytical methods, their advantages and drawbacks}

In order to quantify RS, the main step is to remove the digestible starch from the sample. This is performed using a pancreatic $\alpha$-amylase. In some of the methods, an amyloglucosidase is added in order to avoid a possible inhibition of the $\alpha$-amylase by the products of the digestion (mainly maltose and maltotriose). However, this enzyme, which is of fungal origin, seems to be very active on some specific crystalline structures (Planchot et al. 1997). There is a concern that 'over-digestion' of some RS structures by the cocktail ' $\alpha$-amylase-amyloglucosidase' may occur. The amylolysis is also sometimes preceded by a proteolysis (often pepsin hydrolysis), which is supposed to reflect the action of the pepsin inside the stomach and of the trypsin that is secreted in the pancreatic juice together with the $\alpha$ amylase. 
After hydrolysis of the digestible starch, RS is quantified directly in the residue (usually isolated by $80 \%$ ethanolic precipitation) (Champ, 1992; Faisant et al. 1995b; Champ et al. 1999a) or by calculating the difference between total starch and digestible starch, which are quantified separately (Englyst et al. 1992).

The main methods to measure RS, as described in the literature, will be outlined later (pp. 151-154). In order to give the reader help in understanding the section in which the methods are described, the possibilities that are available for the validation of the methods will now be explained.

\section{Possibilities of validation in vivo}

It is considered that at present three methods are potentially available to obtain the in vivo values on the RS content of foods that are required for a validation of the in vitro methods. These methods have been described in more detail earlier (Champ et al. 1999b).

\section{Hydrogen breath test}

$\mathrm{H}_{2}$ is one of the endproducts of carbohydrate fermentation. It is exclusively formed in the colon by bacterial fermentation, partly absorbed and cleared in a single passage of the lungs to be excreted in the expired air. The results of gas perfusion techniques have suggested that a rather constant fraction of the total $\mathrm{H}_{2}$ production is excreted by the lungs, and that rates of breath $\mathrm{H}_{2}$ excretion correlate well with $\mathrm{H}_{2}$ production (Levitt, 1969). Flourié et al. (1988) used a nonabsorbable but quickly fermented oligosaccharide (lactulose) to 'calibrate' the subject. This was considered to be a good control to allow quantification of malabsorbed carbohydrates. The data are usually obtained by calculating the area under the curve after the test meal:area under the curve after the intake of lactulose value. Knowing the amount of lactulose fermented, the amount of carbohydrate from the experimental meal, which theoretically has been fermented, can be calculated. Even though the principle appears quite simple, there are several theories on the best way to perform this quantification (Rumessen, 1992). Although this procedure is quantitative for oligosaccharides, it is only qualitative for insoluble or slowly fermented substrates. An example of the possible discrepancies between the $\mathrm{H}_{2}$ breath test and a direct method is shown in Table 5 . Malabsorption of two starches, a retrograded high-amylose maize starch and a complexed (to monoacylglycerols) highamylose maize starch, has been measured on healthy subjects using the technique of intubation (Champ et al. 1998) and the breath test (F Bornet, D Cloarec, JL Barry, S Gouilloud, M Champ, P Colonna and JP Galmiche, unpublished results). The respective values are $21 \cdot 1$ and $9 \cdot 2 \%$ for the retrograded high-amylose maize starch and 50.9 and $9 \cdot 5$ $\%$ for the complexed high-amylose maize starch. A possible explanation is linked to the slower production of $\mathrm{H}_{2}$ from RS fermentation than from oligosaccharides. $\mathrm{H}_{2}$ may then be used by bacteria much more extensively than when the production is much higher but over a shorter period. Thus the method is not appropriate for the quantification of RS.
Table 5. Malabsorption of starch estimated in human subjects by different techniques (from Champ et al. 2001)

\begin{tabular}{|c|c|c|}
\hline Source of starch & Starch ingested (g) & Malabsorption (\%) \\
\hline \multicolumn{3}{|l|}{$\mathrm{H}_{2}$ breath test } \\
\hline HACS, raw & 30 & $9 \cdot 2$ \\
\hline HACS, complexed & 30 & 9.5 \\
\hline HACS, retrograded & 30 & $6 \cdot 7$ \\
\hline $\begin{array}{l}\text { Cooked and cooled } \\
\text { potatoes }\end{array}$ & 60 & $22 \cdot 8$ \\
\hline $\begin{array}{l}\text { Cooked, cooled and } \\
\text { warmed-up potatoes }\end{array}$ & 60 & $5 \cdot 0$ \\
\hline White bread & 120 & $10 \cdot 7$ \\
\hline Wholemeal bread & 120 & $8 \cdot 3$ \\
\hline Wheat flour & 50 & $2 \cdot 8$ \\
\hline Whole meal & 50 & $13 \cdot 6$ \\
\hline Oat flakes (raw) & 35 & $7 \cdot 8$ \\
\hline Oat flakes (cooked) & 35 & $5 \cdot 8$ \\
\hline Lentils & 120 & $38 \cdot 0$ \\
\hline Green banana & 100 & $38 \cdot 6$ \\
\hline Banana + rice & n.m. & $0 \cdot 0$ \\
\hline \multicolumn{3}{|l|}{ lleostomy model } \\
\hline Rice + bread & $98-127$ & 0.5 \\
\hline Bread & 107 & 0.8 \\
\hline White bread & 100 & 13 \\
\hline White bread & 61.9 & 2.5 \\
\hline Wholemeal bread & 100 & 11 \\
\hline Oat flakes & $57 \cdot 8$ & $2 \cdot 2$ \\
\hline Cornflakes & $74 \cdot 2$ & $5 \cdot 0$ \\
\hline Freshly cooked potatoes & $45 \cdot 4$ & $3 \cdot 3$ \\
\hline $\begin{array}{l}\text { Cooked and cooled } \\
\text { potatoes }\end{array}$ & $47 \cdot 2$ & 11.9 \\
\hline $\begin{array}{l}\text { Cooked, cooled and } \\
\text { steamed potatoes }\end{array}$ & $47 \cdot 6$ & $7 \cdot 7$ \\
\hline Banana (ripe) & $3 \cdot 0$ & $55 \cdot 7$ \\
\hline Banana (unripe) & $13 \cdot 9$ & 84.0 \\
\hline Lentils & 100 & 21 \\
\hline \multicolumn{3}{|l|}{ Intubation of healthy subjects } \\
\hline HACS, complexed & $32 \cdot 5$ & $21 \cdot 1$ \\
\hline HACS, retrograded & 32.5 & $50 \cdot 9$ \\
\hline Banana (unripe) & $23 \cdot 1$ & $83 \cdot 7$ \\
\hline Banana + rice & 20 & $10 \cdot 2$ \\
\hline \multicolumn{3}{|l|}{ Banana + rice + potatoes } \\
\hline+ beans & 61 & $8 \cdot 0$ \\
\hline Bread + pasta + potatoes & 100 & $5 \cdot 2$ \\
\hline Bread + pasta + potatoes & 300 & $4 \cdot 1$ \\
\hline Beans & 68.5 & $16 \cdot 5$ \\
\hline
\end{tabular}

HACS, high-amylose maize starch; n.m., not measured.

\section{Ileostomy model}

The ileostomy model offers a method for direct and quantitative determination of small-bowel excretion, provided the bacteriological degradation of the effluent can be minimised. The subjects who take part in these studies have had a conventional ileostomy after colectomy, usually for ulcerative colitis. This surgery is performed by eversion of the distal $50-100 \mathrm{~mm}$ of the small bowel, which is pulled onto the abdominal wall as a fistula (Andersson, 1992). The subjects can easily collect their effluent in a bag, which is usually changed every $2 \mathrm{~h}$ during the daytime. The ileostomy bags are immediately deep-frozen on solid carbon dioxide. During the experimental period the subjects are given a plant polysaccharide-free diet with addition of the RS source studied (Langkilde \& Andersson, 1994). 


\section{Intubation technique}

Healthy volunteers are intubated with a triple-lumen polyvinyl tube. The transit of the tube through the gut is assisted by a terminal inflatable bag containing $\mathrm{Hg}$. When the bag reaches the caecum, as confirmed fluoroscopically, it is deflated and the subjects have to remain in a semirecumbent position. One lumen is used to sample ileal content $50 \mathrm{~mm}$ above the ileocaecal junction, and the other lumen, $250 \mathrm{~mm}$ proximal to the aspiration port, is used for perfusion. The perfusate contains $\mathrm{NaCl}$ and polyethylene glycol 4000 as a recovery marker to estimate water flow through the distal ileum (Noah et al. 1998). The solution is maintained at $37^{\circ} \mathrm{C}$ and stirred until the end of perfusion. The day after the intubation, the subjects are given the experimental meal as a breakfast. The intestinal contents are aspirated for $14 \mathrm{~h}$, during which time the subjects do not eat or drink. Intestinal contents are continuously collected by manual aspiration, with the aim to collect as much fluid as possible. Samples, maintained on ice during the collection, are divided into $30 \mathrm{~min}$ portions that are frozen in liquid $\mathrm{N}_{2}$ and then freeze-dried. Maintenance of tube position is confirmed fluoroscopically at the end of all experiments.

A summary of the three main methods outlined (pp. 149-150), showing their advantages and shortcomings, is presented in Table 6 . Some of the results obtained with these methods are presented in Table 5.

\section{Ileostomy model v. intubation technique}

It is difficult to compare the data obtained within different studies with different types of meals and different starch intakes. However, one comparison has been made between two studies performed with the ileostomy model and the ileal intubation method in healthy subjects (Langkilde et al. 1994) with the same meal containing $16 \cdot 3 \mathrm{~g}$ RS (30 g) from green banana. The ileal excretions of starch (i.e. RS) were $15 \cdot 8($ SEM $0 \cdot 4$ ) and $19 \cdot 3$ (SEM 0.7) g/d for the ileostomates and the healthy subjects, respectively. Such a difference can be explained by an underestimation of RS in ileostomates and/or by an overestimation of RS when intubation techniques are used.

Indeed, there is a difference in the microbial population in a normal distal ileum compared with that of the terminal ileum in ileostomy subjects, with $10^{5}-10^{6}$ bacteria/g and $10^{7}-10^{8}$ bacteria/g, respectively (Finegold et al. 1970; Drasar \& Hill, 1974). However, the differences are small compared with the numbers found in the caecum $\left(10^{12} / \mathrm{g}\right)$. If the bags are changed every $2 \mathrm{~h}$ and deep-frozen, the bacterial degradation of NSP and RS is small (Sandberg et al. 1983; Englyst \& Cummings, 1985, 1987; Lia et al. 1996). In the study by Englyst \& Cummings (1985), low amounts of SCFA were found in the ileal effluents and treatment with antibiotics did not change the amounts of carbohydrates recovered. In another study, higher amounts of SCFA and lactic acid in the ileal effluents have been measured following the addition of 10 or $30 \mathrm{~g}$ inulin to the diet in ileostomy subjects (Bach Knudsen \& Hessov, 1995). The amounts of SCFA and lactic acid found were, however, estimated to correspond to about 2-3 g fermented carbohydrate per $\mathrm{d}$. This means that the model may give a slight underestimation of the amount of carbohydrate recovered, especially of easily fermented carbohydrates such as oligosaccharides. In contrast, the intubation is thought to be the cause of a decrease of the oro-ileal transit time due to the tube that could decrease the efficiency of the intestinal digestion.

Thus, in conclusion, two methods are available in principle to quantify RS in vivo in human subjects as 'the sum of starch and products of starch degradation not absorbed in the small intestine of healthy individuals': (1) the intubation technique; (2) the ileostomy model.

The only direct technique available for use on healthy volunteers is the intubation technique. The main drawback of the method is the presence of the tube along the small intestine and its possible influence on the transit of food. In the second method, RS is quantified directly, by collecting ileal samples in human ileostomates. The determination of

Table 6. Advantages and shortcomings of the studies performed with human subjects (from Champ et al. 2001)

\begin{tabular}{|c|c|}
\hline Advantages & Shortcomings \\
\hline $\begin{array}{l}\mathrm{H}_{2} \text { breath test }^{*} \\
\text { Simple and non-invasive } \\
\text { Healthy subjects }\end{array}$ & $\begin{array}{l}\text { Semi-quantitative } \\
\text { Strict standardisation necessary } \\
\text { Large intra- and inter-individual variation in } \mathrm{H}_{2} \text { excretion }\end{array}$ \\
\hline $\begin{array}{l}\text { lleostomy model } \\
\text { Direct collection of the ileal } \\
\text { effluent (i.e. quantitative) } \\
\text { Easy to perform }\end{array}$ & $\begin{array}{l}\text { Cannot be considered as healthy } \\
\text { Physiological adaptation } \\
\text { Water and electrolytes absorption } \\
\text { Bacterial overgrowth } \\
\text { Transit time (different from normal) }\end{array}$ \\
\hline $\begin{array}{l}\text { Intubation of healthy subjects } \ddagger \\
\text { Healthy subjects } \\
\text { Direct collection of the ileal effluent }\end{array}$ & $\begin{array}{l}\text { Disturbance of the normal physiology by the long triple } \\
\text { lumen tube } \\
\text { Quantification of the flow rate using a liquid phase marker } \\
\text { Risk of selectivity of the tube in case of heterogeneous food } \\
\text { Expensive and long }\end{array}$ \\
\hline
\end{tabular}


small-bowel excretion is quantitative, provided the bacterial degradation of the effluent can be minimised. This technique probably slightly underestimates the RS content of the foods. The $\mathrm{H}_{2}$ breath test is also used to quantify malabsorption of starch. It is rapid and simple but indirect and consequently semi-quantitative. However, the use of an appropriate standard for the 'calibration' of the subject may further improve the quality of the method.

\section{Short review of methods to measure resistant starch content}

The main methods as described in the literature will be briefly outlined in the following sections. A summary of the most recent methods is also presented in Table 7.

\section{Method of Björck et al. (1986)}

Principle: this method quantifies that part of the starch present in the dietary fibre residue that is obtained after enzymic solubilisation (bacterial $\alpha$-amylase (Termamyl) treatment at $95-100^{\circ} \mathrm{C}$ ) (according to Asp et al. (1983) and Prosky et al. (1988)), using the Association of Official Analytical Chemists (AOAC) procedure for dietary fibre determination. The soluble dietary fibre components are precipitated with $95 \%(\mathrm{w} / \mathrm{w})$ ethanol and the total dietary fibre components are then recovered by filtration. RS is calculated as the total amount of starch that remains in the fibre residue after solubilisation in $\mathrm{KOH}$, minus the value obtained without prior $\mathrm{KOH}$ treatment.

Advantages, disadvantages and validation: The RS analysis can be performed together with total dietary fibre analysis (AOAC procedure for dietary fibre determination). However, the main component measured is retrograded starch. Indeed, the heat treatment $\left(95-100^{\circ} \mathrm{C}\right)$ solubilises part of the NSP, contributing to a permeabilisation of the cell wall, and gelatinises the native (or not fully gelatinised) starch granules. Even RS3 seems to be underestimated.

This method has been validated with a rat model (antibiotic (nebacitin)-treated rats; Björck \& Asp, 1991) but not in man.

\section{Method of Englyst et al. (1992)}

Principle: The various types of starch are determined by controlled enzymic hydrolysis with measurement of the released glucose using glucose oxidase. In this case RS is defined as the starch that is not hydrolysed after incubation with pancreatin (Pancrex V; Paines and Byrne, Greenford, UK) and amyloglucosidase (Novo Nordisk Bioindustries, Copenhagen, Denmark), after $120 \mathrm{~min}$ at $37^{\circ} \mathrm{C}$. Due to a contamination of amyloglucosidase with an invertase activity, invertase is also added. Sucrose has thus to be determined separately. RS is calculated by deducting the rapidly digestible starch plus the slowly digestible starch contents (i.e. after 20 and 120 min incubation, respectively) of the sample from the total starch content.

Advantages, disadvantages and validation: The conditions of hydrolysis have been optimised and the method has been adapted to a large variety of substrates. However, the method is often considered laborious and gives a poor reproducibility without specialised training in the methodology. Moreover, very specific equipment (mincer, shaking water baths) is needed. The RS content is not measured directly but calculated by taking the difference between total starch and rapidly digestible starch plus slowly digestible starch.

The method is validated in vivo by comparing the results against those obtained with the ileostomy model. An example of such a comparison is shown in Table 8. It appears to be relatively satisfactory. The RS in potato biscuit is probably underestimated, due to the glass balls. However, it is unexpected that the same discrepancy is not seen with banana biscuits, if these are made from green banana as the main ingredient.

\section{Method of Muir \& O'Dea $(1992,1993)$}

Principle: A chewed food sample is incubated with pepsin and then hydrolysed by $\alpha$-amylase (Speedase PNA-8; Halcyon Chemicals, Sandringham, Australia) and amyloglucosidase (Sigma, St Louis, MO, USA). The insoluble (in water; no alcoholic precipitation) residue, collected by centrifugation, contains RS.

Advantages, disadvantages and validation: From the data available, in vitro and in vivo, on seven different foods, it seems to be a satisfactory method with acceptable reproducibility. However, no comparisons with other in vitro methods have been published and, until now, mainly the original authors have used it making it difficult to evaluate. The method has been validated with in vivo studies on ileostomates (Muir \& O’Dea, 1993; Muir et al. 1995) (Table 9) and the predictive power of the in vitro method seems satisfactory. However a slight discrepancy appears with some of the samples such as baked beans or low- and highRS meals.

\section{Method of Goñi et al. (1996)}

Principle: The food sample is milled (dry samples) or homogenised (wet samples), defatted when fat content is equal or higher than $5 \%$, incubated with pepsin, and then hydrolysed by pancreatic $\alpha$-amylase. The water-insoluble residue (no alcoholic precipitation), collected by centrifugation, contains RS. Similar to several other methods (Champ, 1992; Faisant et al. 1995b; Champ et al. 1999a) the Goñi et al. (1996) method is derived from the earlier established Berry (1986) procedure.

Advantages, disadvantages and validation: The method does not involve the use of amyloglucosidase. This is advantageous for samples containing RS that are sensitive to fungal amyloglucosidase. It has been identified by Dysseler \& Hoffem (1994b) as the best method based on the duration of the procedure and the costs, when compared with the other methods derived from the Berry (1986) and the Englyst et al. (1992) methods. However, this method has not been directly validated using human subjects but the authors have used in vivo data available in the literature for the validation.

Method of Åkerberg et al. (1998)

Principle: The analytical procedure was chosen to mimic physiological conditions and included chewing as a pre- 


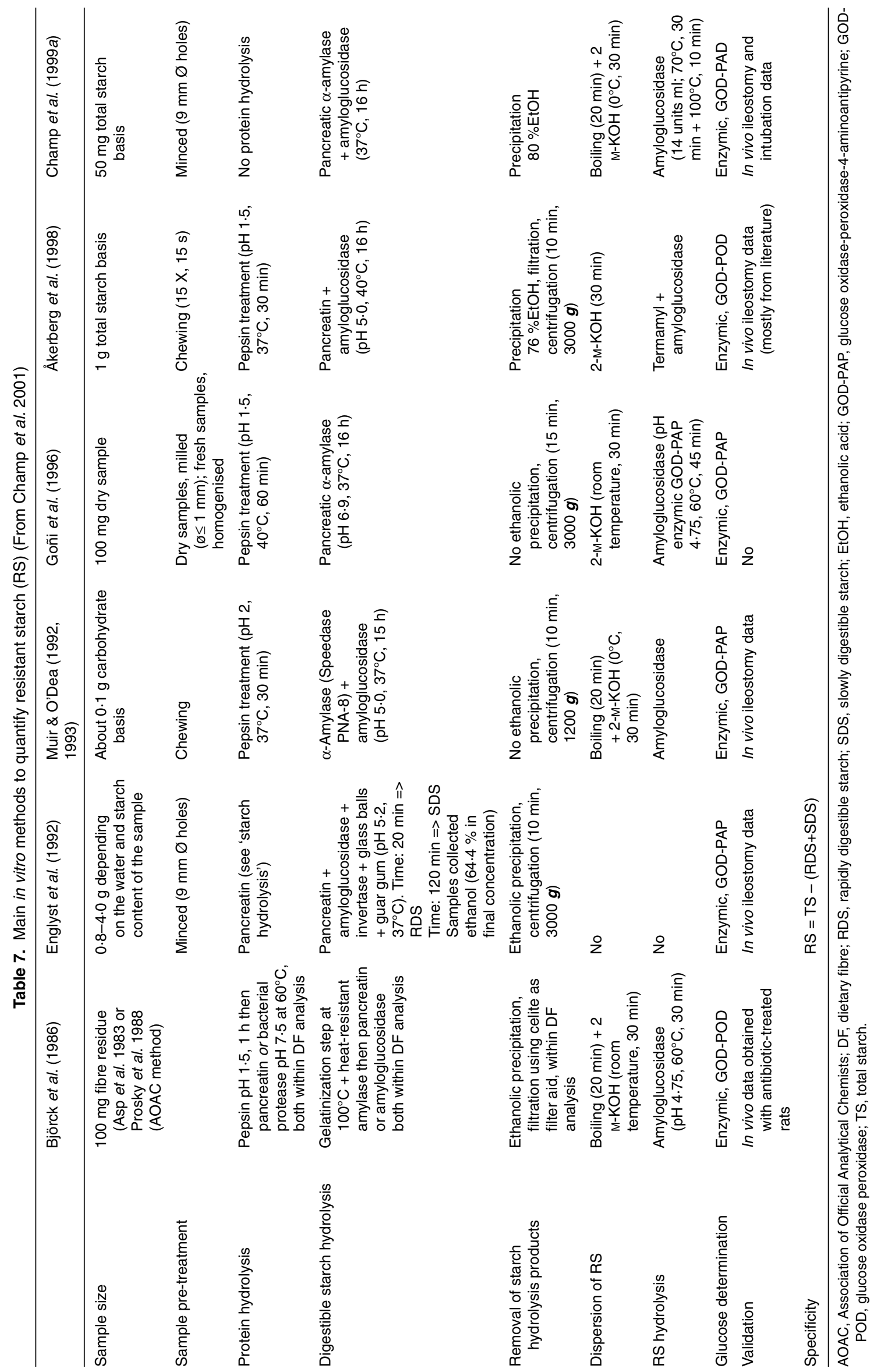


Table 8. In vivo recovery of resistant starch (RS) (g/100 g dry matter) from different sources of RS in ileostomates (from Englyst et al. 1992)

\begin{tabular}{llll}
\hline Source of starch & Fed $^{*}(\mathrm{~g})$ & RS recovered $(\mathrm{g})$ & Mean recovery $(\%)$ \\
\hline Wheat biscuit & 0 & 0.3 & - \\
Wheat RS biscuit & 8.5 & 9.0 & 106 \\
Maize RS biscuit & 8.5 & 8.6 & 101 \\
Potato biscuit & 11.7 & 13.7 & 117 \\
Banana biscuit & 15 & 13.7 & 91 \\
\hline
\end{tabular}

* Determined according to in vitro method described by Englyst et al. (1992).

Table 9. In vivo recovery of resistant starch (RS) ( $\mathrm{g} / 100 \mathrm{~g}$ dry matter) from different sources of RS in ileostomates (from Muir \& O’Dea 1993; Muir et al. 1995)

\begin{tabular}{llllll}
\hline & \multicolumn{2}{c}{ Starch $(\mathrm{g})$} & & \multicolumn{2}{c}{ Percentage RS } \\
\cline { 2 - 3 } \cline { 5 - 6 } Source of starch & Ingested $^{*}$ & Recovered & & In vivo & In vitro \\
\hline High-RS meal & 52.7 & 19.9 & & 37.8 & 35.1 \\
Baked beans & 22.7 & 1.3 & & 5.7 & 6.9 \\
Pearl barley & 41.0 & 2.3 & & 5.5 & 5.5 \\
Low RS meal & 51.8 & 2.4 & & 3.6 & 3.1 \\
Cornflakes & 44.1 & 1.4 & & 3.1 & 2.9 \\
Whole rice & 48.9 & 1.5 & 0.7 & 2.7 \\
Ground rice & 46.1 & 0.3 & & 0.8 \\
\hline
\end{tabular}

* Determined according to in vitro method described by Muir \& O'Dea (1993).

step before incubation with pepsin, pancreatin (Sigma) and amyloglucosidase (Boehringer, Mannheim, Germany). The non-digestible polysaccharide, including RS, is recovered by ethanol precipitation and subsequent filtration. RS is analysed as total starch in the filter residue.

Advantages, disadvantages and validation: According to the authors, the method allows parallel determination of the potentially available starch fraction and dietary fibre. The method has been mainly validated on the basis of in vivo values from the literature. The relationship obtained, between in vivo and in vitro values, on nineteen foods was: $y=0.77 x+0.45(r 0.97)$. The repeatability of the method seems to be good, as the pooled standard deviation for the method is $2.9 \%$.

\section{Method of Champ et al. (1999a)}

Principle: In vitro the RS content is defined as the starch that is not hydrolysed by incubation with $\alpha$-amylase and amyloglucosidase. Amyloglucosidase (Novo Nordisk) is added to the pancreatic $\alpha$-amylase (Sigma) to avoid inhibition of the amylase by the products of the digestion. The inclusion of amyloglucosidase was one of the main modifications to the Berry (1986) method. Hydrolysis products are extracted with $80 \%(\mathrm{w} / \mathrm{w})$ ethanol and discarded. RS is then solubilised with $2 \mathrm{M}-\mathrm{KOH}$ and hydrolysed with amyloglucosidase. The current method is derived from the earlier one published in 1992 within the EURESTA project (Champ, 1992), which itself was derived from the Berry (1986) method.

Advantages, disadvantages and validation: The authors consider the method as simple and relatively rapid. Ten samples can easily be analysed (in duplicate) in a normal working day and no particular training is needed. However, the amyloglucosidase is no longer available from Novo
Nordisk Bioindustries. Moreover, there is no proteolysis step, which may be a problem with substrates containing a high percentage of protein, even if such problems have never been observed by the authors (even with grain legumes). The procedure has been validated using in vivo values obtained from ileostomates as well as data from intubation studies (Faisant et al. 1995a; Champ et al. 1998; Noah et al. 1998). When compared with in vivo data obtained on ileostomates with the same starchy foods (Table 10) the method appears to be satisfactory. However, when compared with data obtained in healthy subjects by the intubation technique, it underestimates the RS values, except in the case of canned beans. Indeed, the intubation technique always provides higher RS values than the ileostomy model. The exception of the canned beans is most probably due to a partial collection of the bean residues in the ileum caused by the presence of large particles (Noah et al. 1998). Ideally, more comparisons should be performed between in vitro and in vivo values to check the validity of the method for the in vitro measurement of a large range of starches and foods.

\section{Method of McCleary \& Monaghan (2002)}

Principle: The intention of McCleary was to develop a simple but reliable in vitro method to measure true RS, i.e. the fraction of starch that enters the large intestine.

For this purpose different starches and food products for which in vivo RS data on absorbed and non-absorbed fractions existed from studies in ileostomy patients were used as test materials. McCleary \& Monaghan (2002) took into account the strengths and weaknesses of the other methods as described earlier (Englyst et al. 1992; Muir \& O’Dea, 1992, 1993; Goñi et al. 1996; Åkerberg et al. 1998; Champ et al. 1999a). 
Table 10. Comparison of resistant starch (RS) (as percentage total starch) determined in vivo and in vitro

\begin{tabular}{|c|c|c|c|c|c|c|}
\hline Source of starch & \multicolumn{5}{|c|}{ In vitro $\mathrm{RS}$} & In vivo $\mathrm{RS}$ \\
\hline HACS, raw & 71.4 & $72 \cdot 2$ & $52 \cdot 8$ & & $51 \cdot 7 \dagger \dagger$ & $50.3 \dagger$ \\
\hline HACS, retrograded & 30.5 & $36 \cdot 4$ & $29 \cdot 6$ & & 42.0†† & $30 \cdot 1 \dagger$ \\
\hline Bean flakes & $10 \cdot 6$ & $12 \cdot 4$ & $11 \cdot 2$ & & $14.3+\dagger$ & $9-10.9 \ddagger$ \\
\hline Cornflakes & 3.9 & 4.9 & $4 \cdot 3$ & & $4.0 \dagger \dagger$ & $3 \cdot 1-5 \cdot 0 \S$ \\
\hline
\end{tabular}

HACS, high-amylose maize starch.

†lleostomy model; AM Langkilde, $\mathrm{H}$ Andersson and $\mathrm{F}$ Bouns (personal communication).

†lleostomy model; Schweizer et al. (1988).

§lleostomy model; Muir \& O'Dea (1993) and Englyst et al. (1992).

Illntubation technique; Noah et al. (1998).

ףIntubation technique; analysis by Dr Kettlitz, Cerestar Research and Development Centre, Vilvoorde, Belgium.

††Intubation technique; presented at AACC Meeting in Montreal 13-17 October, 2002.

The following parameters were studied systematically:

- concentration of pancreatic $\alpha$-amylase;

- need for pepsin pre-treatment;

- $\mathrm{pH}$ of incubation;

- importance of maltose inhibition of $\alpha$-amylase;

- need for amyloglucosidase inclusion;

- effect of shaking and stirring on obtained RS values;

- problems in recovering and analysing the RS-containing pellets.

This systematic study has led to a procedure omitting a pepsin pre-digestion and consisting of the joint action of pancreatic $\alpha$-amylase and amyloglucosidase at $\mathrm{pH}$ 6.0 under defined shaking conditions followed by alcohol precipitation. After dissolution in $2 \mathrm{~m}-\mathrm{KOH}$, RS is hydrolysed by amyloglucosidase and glucose is measured by using the GODPOD reagent (glucose oxidase-peroxidase reagent; Megazyme International Ireland Ltd, Wicklow, Republic of Ireland).

Compared with other and earlier published RS methods, this method shows most similarity to the method of Champ et al. (1999a).

Table 10 represents data from in vitro RS tests obtained by different methods compared with in vivo data using the ileostomy method (McCleary \& Monaghan, 2002). Megazyme Ltd (Bray, County Wicklow, Republic of Ireland) is providing a test kit for the McCleary \& Monaghan (2002) RS method. The complete method is also described at www.megazyme.com/booklets/KRSTAR.pdf

It is expected that this method will become generally accepted and will replace the other RS methods in future in the same manner as the introduction of AOAC method 985.29 (Prosky et al. (1985) led to a harmonisation for the determination of total dietary fibre. A slight adaptation of AOAC method 985.29 will be necessary in order to avoid a partial overlap with AOAC method 2002.02. BV McCleary, D Monaghan and M McNally (personal communication) have presented a corresponding proposal recently consisting of the incorporation of a dimethyl sulfoxide solubilisation step in the total dietary fibre assay procedure according to method 985.29.

\section{Results of these methods when applied to different products}

Few comparisons have been performed using different methods, while analysing exactly the same samples. Champ (1992) and Englyst et al. (1992) have published such a comparison, within the EURESTA programme (Table 11). As expected, the method of Björck et al. (1986) (quantification of RS in AOAC dietary fibre residue) gave the lowest values. However, the significant underestimation was observed only for native and treated pure starches (raw potato starch and pregelatinised highamylose maize starch). In 1996, the same author (Björck, 1996) criticised the use of thermostable $\alpha$-amylase in the (dietary fibre) AOAC method since neither botanically encapsulated starch nor raw starch granules are recovered. Moreover, the author also pointed out that incubation with Termamyl at elevated temperatures may to some extent also dissociate firmly retrograded amylose'. This last statement is mainly based on work published by Würsch \& Koellreuter (1992). The Englyst et al. (1992) and Champ (1992) methods gave very similar values. The method modified by Faisant et al. (1995b) gave a significantly higher value of RS for the raw potato starch. This value is closer to the in vivo value obtained with ileostomates. This result was later confirmed by the data published by Langkilde \& Andersson (1994). The new method of Champ et al. (1999a) has been compared with the method of Englyst et al. (1992) on samples of fresh and mashed beans. Both methods provided exactly the same results: $7 \cdot 3 \mathrm{~g} \mathrm{RS} / 100 \mathrm{~g} \mathrm{DM}$.

Another comparison has been published in 1994, within the EURESTA project, by Dysseler \& Hoffem $(1994 b)$. Table 12 shows some of the analyses made during this collaborative study. This study reveals that the Berry (1986) method modified by Saura-Calixto (in fact the Goñi et al. (1996) method) gives similar values for high-amylose maize starch, bean flakes and white bread as both Englyst et al. (1992) and Champ (1992) methods. For white bread (with double emulsifier), the Champ (1992) and Goñi et al. (1996) methods gave a similar result that is lower than with the Englyst et al. (1992) 
Table 11. Analysis of resistant starch ( $\mathrm{g} / 100 \mathrm{~g}$ dry matter) in different sources of starch with different in vitro methods (from Champ et al. 2001)

\begin{tabular}{|c|c|c|c|c|c|}
\hline Source of starch & Björck et al. (1986) & Englyst et al. (1992) & $\begin{array}{l}\text { Champ (1992) } \\
\text { (method A) }\end{array}$ & Faisant et al. (1995a) & Noah et al. (1998) \\
\hline $\begin{array}{l}\text { Potato starch, raw } \\
\text { HACS, raw }\end{array}$ & 0.2 & $\begin{array}{l}64 \cdot 9 \\
68 \cdot 8\end{array}$ & $66 \cdot 2$ & $\begin{array}{l}85 \cdot 3 \\
67 \cdot 3\end{array}$ & \\
\hline HACS, retrograded & & $30 \cdot 0$ & & $35 \cdot 3$ & \\
\hline HACS, pregelatinised & $9 \cdot 6$ & $16 \cdot 3$ & $15 \cdot 7$ & & \\
\hline Bean flakes & 4.3 & $5 \cdot 0$ & $5 \cdot 0$ & 4.5 & \\
\hline Cornflakes & $2 \cdot 3$ & $2 \cdot 4$ & $2 \cdot 8$ & $2 \cdot 8$ & \\
\hline Beans (fresh) & & $7 \cdot 3$ & & & $7 \cdot 3$ \\
\hline
\end{tabular}

HACS, high-amylose maize starch.

method. For banana flour the results are all very different from each other. Finally a comparison of Champ (1992), Goñi et al. (1996), Berry (1986) and Björck et al. (1986) methods on four samples (retrograded debranched maltodextrin of three different botanical origins produced by Cerestar and one commercially available product; Novelose 330) (Table 13) confirms that the quantification of RS from the AOAC dietary fibre residue (Björck et al. 1986) provides much lower values than the three other methods. Among those three methods, the Berry (1986) method provided the highest values whereas the Champ (1992) method provided the lowest (B Kettlitz, Cerestar, personal communication). A very recent in vivo study on ileostomates (AM Langkilde, personal communication) on retrograded debranched maltodextrin (Actistar from Cerestar) reveals that the non-digestible fraction in vivo amounts to $54 \%$ RS (total-starch basis) (59\% on a DMbasis) and that this result is compares well with in vitro data that have been obtained with specific methods for the quantification of the content of RS in food, especially the Champ (1992), Goñi et al. (1996) and McCleary \& Monaghan (2002) methods (Table 10). In comparison, when quantified according to the AOAC method 985.29 (Prosky et al. 1985) the product contains only a negligible amount of dietary fibre (Table 13). This underlines the fact that an accurate in vitro measurement of RS in food cannot be performed by an adaptation of the current AOAC method for dietary fibre. Instead, a specific method, such as the one recently developed by McCleary \& Monaghan (2002), is required.

\section{Analytical validation (ring tests)}

There are very few collaborative studies undertaken on RS analysis. Two such studies have been published (in 1992) within EURESTA (European Flair Concerted Action no. 11 (COST 911) entitled 'Physiological implications of the consumption of resistant starch in man') in a supplement volume of the European Journal of Clinical Nutrition (Anonymous, 1992).

\section{Englyst et al. (1992)}

Eight laboratories participated in a collaborative trial of the procedure of the Englyst et al. (1992) method, described in the present paper. These laboratories (eight out of ten) were selected after the analysis of two pre-trial samples of unknown composition. For the two pre-trial samples and the six trial samples, the mean reproducibility (i.e. $\mathrm{SD} \times 2 \cdot 8$ ) was $5 \cdot 3$ for total starch and $8 \cdot 2$ for RS. Taking into account the small number of participants, the results were regarded by the authors as satisfactory but the trial was considered as a preliminary study.

\section{Champ (1992)}

In the Champ (1992) study two methods were compared by eighteen laboratories. Method A was based on the procedure described by Berry (1986), as later modified by AA Rivellese (personal communication) and then by Champ (1992). Method B was proposed by Asp et al. (1983). In

Table 12. Analysis of resistant starch ( $\mathrm{g} / 100 \mathrm{~g}$ as received) in different sources of starch with different in vitro methods (from Dysseler \& Hoffem, 1994b)

\begin{tabular}{|c|c|c|c|}
\hline Source of starch & Englyst et al. (1992) & Champ (1992) (method A)* & Goñi et al. (1996)† \\
\hline Banana flour & $50 \cdot 34$ & 26.99 & $40 \cdot 9$ \\
\hline HACS, retrograded 3 & $25 \cdot 16$ & $27 \cdot 32$ & $31 \cdot 25$ \\
\hline Bean flakes & 4.76 & 4.49 & 4.83 \\
\hline White bread & $1 \cdot 36$ & $1 \cdot 36$ & 1.54 \\
\hline $\begin{array}{l}\text { White bread + } \\
\text { double emulsifier }\end{array}$ & $1 \cdot 71$ & $1 \cdot 32$ & $1 \cdot 38$ \\
\hline
\end{tabular}


Table 13. Comparison of resistant starch (RS) content (\%) obtained by different methods on four RS products†

\begin{tabular}{llllll}
\hline RS product & Starch origin & $\begin{array}{l}\text { Champ } \\
\text { et al. (1999a) }\end{array}$ & $\begin{array}{l}\text { Goñi } \\
\text { et al. (1996) }\end{array}$ & $\begin{array}{l}\text { Berry } \\
(1986)\end{array}$ & $\begin{array}{l}\text { Prosky et al. } \\
\text { (1988) (AOAC) }\end{array}$ \\
\hline $\mathrm{C}^{*}$ 019R0 $\ddagger$ & Tapioca & 56.7 & 58 & 66 & $<0.5$ \\
$\mathrm{C}^{*}$ 019R5 $\ddagger$ & Potato & 43.6 & 48 & 56 & 0.7 \\
$\mathrm{C}^{*}$ 019R6 & Maize & 53.4 & 54 & 62 & 0.7 \\
Novelose 330 & High-amylose maize & $36 \cdot 8$ & 46 & 57 & 27 \\
\hline
\end{tabular}

AOAC, Association of Official Analytical Chemists.

† Data provided by B. Kettlitz (Cerestar Research and Development, Vilvoorde, Belgium).

$\ddagger$ Retrograded debranched maltodextrin.

this method, RS was defined as the starch remaining in the fibre residue (Asp et al. 1983; Prosky et al. 1988) and as such available for amyloglucosidase digestion only after solubilisation with $2 \mathrm{M}-\mathrm{KOH}$. The reproducibility of the modified Berry method (A) was poor for some of the samples whereas the proposed Asp method (B) underestimated the RS content in most of the samples, especially in native potato starch and a pregelatinised high-amylose starch.

A comparison was made between data obtained by the Englyst et al. (1992) method and the Champ (1992) method as the same samples have been used in both collaborative trials (Table 14). From this comparison it seems clear that, based on the samples that have been analysed, both the Englyst et al. (1992) method and the Champ (1992) method give similar results, except for raw potato starch (higher value by the Englyst et al. (1992) method). When the results of all laboratories that took part in the trials were pooled, the amount of RS was higher with the Champ (1992) method, except for raw potato starch. Both these observations can easily been explained by an insufficient hydrolysis of 'digestible starch'. The lower value for RS in the case of Champ's (1992) method is explained by a poor dispersion of the RS fraction of the potato starch, before its hydrolysis into glucose. This is confirmed by the values of total starch when quantified by both groups of laboratories that took part in the ring study.

\section{McCleary et al. (2002a)}

Very recently McCleary et al. (2002a) performed another interlaboratory study with thirty-seven collaborators. For the first time excellent results concerning reproducibility and repeatability for an in vitro RS method were obtained. This has led to the recent official approval of the McCleary
\& Monaghan (2002) (Megazyme) RS method identified as AOAC method 2002.02 and American Association of Cereal Chemists method 32-40.

\section{Possible overlap between methods for total fibre or non- starch polysaccharides and resistant starch}

For an appropriate quantification there should not be any overlap between the methods that measure and quantify total fibre, NSP and RS. Generally speaking, starch is usually considered to be totally removed enzymically after solubilisation during the isolation of the fibre residue. However, from our own experience it seems that some fractions of highly RS cannot be completely dispersed with dimethyl sulfoxide. It is unclear to the authors whether the impact of this phenomenon on NSP has ever been properly evaluated.

The Prosky total fibre method (AOAC; Prosky et al. 1984) involves the gelatinisation of dried foods at $95-100^{\circ} \mathrm{C}$ and subsequent hydrolysis of digestible starch with a heat stable $\alpha$-amylase. This is subsequently followed by enzymic digestion with protease and amyloglucosidase to remove protein and the residual 'digestible' starch as well as dextrins. The method has been the subject of several modifications since its inception, the most recent being that of Lee et al. (1992).

A series of collaborative trials have also been performed. The results have shown that the gravimetric residues contain primarily indigestible polysaccharides, including some RS, non-carbohydrate material including lignin, and unidentified substances (Englyst et al. 1996b).

The EURESTA project (1992) involving fourteen laboratories included a comparison of the starch content in the residues obtained after ethanol precipitation from four different food samples. This was done by two methods: (1) by

Table 14. Comparison between analytical results obtained with the methods of Englyst et al. (1992) and Champ (1992)

\begin{tabular}{|c|c|c|c|c|c|c|c|c|}
\hline & \multicolumn{4}{|c|}{ Englyst et al. (1992) (g/100 g DM) } & \multicolumn{4}{|c|}{ Champ (1992) (g/100 g DM) } \\
\hline & \multicolumn{2}{|c|}{ Englyst } & \multicolumn{2}{|c|}{ All } & \multicolumn{2}{|c|}{ Lab 10} & \multicolumn{2}{|c|}{ All } \\
\hline & RS & TS & RS & TS & $\mathrm{RS}$ & TS & $\mathrm{RS}$ & TS \\
\hline $\begin{array}{l}\text { Unmilled bean flakes } \\
\text { Milled bean flakes }\end{array}$ & 6 & $\begin{array}{l}49 \\
5 \cdot 0\end{array}$ & $\begin{array}{c}4 \cdot 8 \\
48 \cdot 3\end{array}$ & $\begin{array}{c}45 \cdot 7 \\
6 \cdot 1\end{array}$ & $\begin{array}{c}5 \cdot 4 \\
40 \cdot 0\end{array}$ & $49 \cdot 1$ & $6 \cdot 6$ & $41 \cdot 1$ \\
\hline Pregelatinised high-amylose starch & 17 & 98 & 11.5 & $90 \cdot 4$ & $15 \cdot 7$ & 95.5 & $19 \cdot 0$ & $78 \cdot 1$ \\
\hline Corn flakes* & 3 & 78 & 4.4 & 74.4 & $2 \cdot 8$ & $76 \cdot 7$ & 3.9 & $65 \cdot 5$ \\
\hline Raw potato starch & 75 & 99 & $56 \cdot 6$ & $82 \cdot 0$ & $66 \cdot 2$ & $94 \cdot 0$ & $55 \cdot 4$ & $82 \cdot 0$ \\
\hline
\end{tabular}

RS, resistant starch; TS, total search; Lab, laboratory.

* Different batch but same brand in both the trials of Englyst et al. (1992) and Champ (1992). 
the Prosky et al. (1984) procedure; (2) by the Berry (1986) procedure. The project has shown that the Prosky et al. (1984) procedure leads only to a partial detection of RS compared with the detection by an RS-specific method (Tables 13 and 15). It has also been shown that incubation with bacterial $\alpha$-amylase to some extent may also dissociate firmly retrograded amylose (RS3) (Würsch \& Koellreuter, 1992). Thus, it seems that the Prosky et al. (1984) procedure does not detect all the types of RS (RS1, RS2 and RS3). Accordingly, when the Prosky et al. (1984) and McCleary \& Monaghan (2002) methods are both applied, one will measure a fraction of the RS twice. This may be corrected by measuring starch in the ethanol precipitate (AOAC method 996.11) and correct for this value (substraction). Champ (1992), in the course of a collaborative study, observed that the repeatability and reproducibility of such measurement of starch in the fibre residue is fairly good. A modification of AOAC method 985.29, as McCleary \& Monaghan (2002) have suggested, is further desirable, as it will improve the analysis. Thus, it is suggested that, for products that may contain a significant amount of RS, it should be allowed to use AOAC method 2002.02 for the measurement of dietary fibre, as a complement of AOAC method 985.29, subject to the correction described earlier in the present paragraph.

\section{Proposed method(s) for resistant starch measurement in foods}

$\mathrm{RS}$, as described in the physiological definition, is composed not only of strictly RS but also of potentially digestible fractions. None of the RS methods presently available have been shown to analyse all RS as defined. However, as discussed earlier (p. 150), several methods have been proposed for the measurement of RS, and some of these have been validated on a quantitative basis with in vivo data obtained on healthy subjects. These have generally provided acceptable values, but most of these methods are not exempt from criticism. The method proposed by Englyst et al. (1992) has been optimised to be applicable to most foods; however, it is laborious and offers poor reproducibility unless technicians undergo specific training. Muir \& O'Dea (1993) developed a new method based on the method of Englyst et al. (1992). Unfortunately, no comparison with other methods is available and it has apparently not been used outside Australia. The number of comparisons with in vivo data is still too limited to draw any conclusions on its validity. The methods of Champ et al. (1999a) and Goñi et al. (1996) were shown to provide similar values to those obtained with the method of Englyst et al. (1992), but have the advantage of being much simpler to use by laboratory technicians and less costly. Regarding the method of Champ et al. (1999a), some comparisons have been performed with in vivo values obtained in ileostomates and in healthy subjects but more comparisons are necessary. There is limited in vivo comparison with the method of Goñi et al. (1996) (Table 10). However, the latter method is preferred by some groups, as it is even simpler than the Champ et al. (1999a) method. Moreover, there is no use of fungal amyloglucosidase, which seems to be a major problem in some cases (crystallites that are very resistant to human enzymes but not to this enzyme of non-animal origin). From the information presented earlier (Table 10) it is apparent that the methods of Englyst et al. (1992) and Champ et al. (1999a) give reliable results and that the method of Goñi et al. (1996) still awaits in vivo validation. Finally, it appears that the method of McCleary \& Monaghan (2002) as recently accepted by the AOAC (2002.02) results in data that are very close to those obtained in vivo with ileostomy patients and may be most favourable for extensive routine use in quality control by the food industry and in official food inspection.

\section{Resistant starch content and food labelling}

As the RS content may change due to processing and preparation of foods the question concerning which RS content should be mentioned on the food product label becomes a relevant one. Should it be the RS content of the food as sold or as consumed?

Two influential factors are of particular relevance for the content of RS: product ageing and culinary preparation of the food. The first concerns the increase or decrease of RS content in the food product that is stored for several months after its production. Indeed, most canned and frozen foods that contain starch will probably generate RS (retrograded amylose and amylopectin). In banana, RS2 decreases during ripening. However, 'dry' foods such as biscuits and rusks do not seem to be susceptible to storage-induced RS content changes.

It is understood that this kind of variation of the nutrient content is already clearly taken into account by current US compliance policies (21 Code of Federal Regulations $101 \cdot 9(\mathrm{~g})(3)$ and (4)). It is also the case in Europe, under the obligation to declare an average content in the product related to the consumption period on the product label (EEC directive 90/496, art. 6, 8). In the USA as well as in Europe, it is the responsibility of the industry to assure the validity of the information, having considered the different influential factors that may contribute to a variation in the nutrient content.

Table 15. Comparison of the amount of resistant starch (RS) in four food samples as determined by the Berry (1986) procedure and in the ethanol precipitate of the Prosky et al. (1984) procedure

\begin{tabular}{lclll}
\hline Sample & Berry RS (\%) & Prosky RS (\%) & Berry - Prosky (\%) & Prosky RS/ Berry RS $\times 100$ \\
\hline Milled bean flakes & 5.66 & 4.67 & +0.99 & 82.5 \\
Pregelatinised high-amylose starch & 17.69 & 8.91 & +8.77 & 50.4 \\
Cornflakes & 3.67 & 1.48 & +2.19 & 40.3 \\
Raw potato starch & 47.8 & 0.12 & +47.61 & 0.25 \\
\hline
\end{tabular}

\footnotetext{
* Expressed as total starch detected in the dietary fibre residue.
} 
In consideration of the second factor, modification of the RS content during the preparation of the food at home, it is obvious that heating a product at a temperature higher than the gelatinisation temperature of the starch (approximately above $70^{\circ} \mathrm{C}$ ), followed by subsequent cooling, will result in retrogradation of amylose and thus in an increase in the amount of RS3. On the other hand, RS when heated can lose its crystalline properties. This is the case for RS2 (native starch granules) for temperatures of about $65^{\circ} \mathrm{C}$ but also for most common RS3 at temperatures above $120^{\circ} \mathrm{C}$. This evolution of starchy foods during cooking and storage will thus have to be considered in labelling, in particular for products for which the most usual home preparations increase the RS amount. In the USA, the current regulations prescribe that the declaration must be related to the product as sold. However, there is also the option to add information on the product as being prepared ("two columns labelling'). This two-column option seems to be required for products in which significant amounts of RS may appear during food preparation.

In Europe the manufacturer may choose to declare the content of a substance either in the product as sold or in the product as prepared. Thus, compliance with these two conditions is of particular importance. Accordingly, instructions for the consumption preparation must be clear and fully detailed (art. 6, 4 of EEC directive 90/496).

As far as RS content is concerned, the authors of the present paper would recommend the mentioning of this information considering an average duration of storage of the product (depending on the category of food) and prepared as mentioned on the instructions for preparation.

For products in which usual home preparations decrease the amount of $\mathrm{RS}$, a recommendation to declare the content in the product as prepared (in place or in addition to the content in the product as sold) seems of particular importance when the starch content in the food is not negligible. The adoption of specific provisions might not be required because under general current rules a food that is cooked as usual and contains significantly less RS than declared on the label would be regarded as misbranded.

\section{Conclusion}

In conclusion, validated analytical methods are available for the determination of the average RS content in foods. These methods can be used in a consistent manner to establish appropriate product labelling to inform the consumer. However, there are different categories of RS that should all be measured (retrograded starches, native RS and physically inaccessible starches) by the analytical method of choice, since these categories are mutually included in the definition. Accordingly it is not appropriate to consider only the part of the retrograded starch as analysed by the AOAC official method for dietary fibre analysis as being the real RS content. Rather it is preferred to realise a proper quantification of the different categories of RS that will result in the true total $\mathrm{RS}$ content. As a consequence, the use of the AOAC procedure to quantify dietary fibre should: (1) reflect a quantification of the residual starch in the fibre residue; (2) include additional methods to quantify RS as well as oligosaccharides and other dietary fibres that are not quantified by this method. In this respect no risk of overlap should exist between the additional methods and the AOAC dietary fibre method.

Accordingly, the method of McCleary \& Monaghan (2002) (AOAC 2002.02) to measure RS should fit these considerations.

Finally, an increase or decrease of the RS content in food during ripening, cooking and cooling does not seem to be an obstacle for appropriate consumer information. With the methods and the food labelling proposed, food manufacturers have the options, but also the responsibility, to declare a value that fairly represents the true content of the product. For foods that contain a significant amount of RS, the variations during storage and home preparation should be taken into account. It should be determined whether (1) declaration should be on the basis of the product as packaged and/or as prepared (Europe) or (2) a two-column labelling should be used with the first column listing the 'as packaged' values and the second column listing the 'as prepared' values (USA).

\section{References}

Achour L, Flourié B, Briet F, Franchisseur C, Bornet F, Champ M, Rambaud JC \& Messing B (1997) Metabolic effects of digestible and partially indigestible cornstarch: a study in the absorptive and postabsorptive periods in healthy humans. American Journal of Clinical Nutrition 66, 1151-1159.

Åkerberg AKE, Liljeberg HGM, Granfeldt YE, Drews AW \& Björck IME (1998) An in vitro method, based on chewing, to predict resistant starch content in foods allows parallel determination of potentially available starch and dietary fiber. Journal of Nutrition 128, 651-660.

Andersson H (1992) The ileostomy model for the study of carbohydrate digestion and carbohydrate effects on sterol secretion in man. European Journal of Clinical Nutrition 46, Suppl. 2, S69-S76.

Anonymous (1992) Resistant Starch. Proceedings for the 2nd plenary meeting of EURESTA: European FLAIR Concerted Action No. 11 on physiological implications of the consumption of resistant starch in man. Crete, 29 May-2 June 1991. European Journal of Clinical Nutrition 46, Suppl. 2, S1-S148.

Asp NG (1992) Resistant starch - Proceedings from the second plenary meeting of EURESTA: European FLAIR Concerted Action No.11 on physiological implications of the consumption of resistant starch in man. Preface. European Journal of Clinical Nutrition 46, Suppl. 2, S1

Asp NG, Johansson CG, Hallmer H \& Siljeström M (1983) Rapid enzymatic assay of insoluble and soluble dietary fiber. Journal of Agricultural and Food Chemistry 31, 476-482.

Asp NG, van Amelsvoort JMM \& Hautvast JGAJ (1996) Nutritional implications of resistant starch. Nutrition Research Reviews 9, 1-31.

Bach Knudsen KE \& Hessov I (1995) Recovery of inulin from Jerusalem artichoke (Helianthus tuberosus L.) in the small intestine of man. British Journal of Nutrition 74, 101-113.

Baghurst PA, Baghurst KI \& Record SJ (1996) Dietary fibre, nonstarch polysaccharides and resistant starch - a review. Food Australia 48, Suppl., S1-S36.

Berry CS (1986) Resistant starch formation: formation and measurement of starch that survives exhaustive digestion with amylolytic enzymes during the determination of dietary fibre. Journal of Cereal Science 4, 301-314.

Björck I (1996) Starch: Nutritional aspects. In Carbohydrates in 
Food, pp. 505-553 [AC Eliasson, editor]. New York, NY: Marcel Dekker Inc.

Björck I \& Asp NG (1991) Balance experiments in nebacitin-treated rats. In Methodological Aspects of In Vivo Methods for Measurement of Starch Digestibility, European Flair Concerted Action on Resistant Starch, contract no. AGRF/0027, pp. 35-39 [E Gudmand-Hoyer, editor]. Copenhagen, Denmark: Gentofte University.

Björck I, Nyman M, Pedersen B, Siljeström M, Asp NG \& Eggum BO (1986) On the digestibility of starch in wheat bread studies in vitro and in vivo. Journal of Cereal Science 4, 1-11.

Blottière HM, Champ M, Hoebler C, Michel C \& Cherbut C (1999) Les acides gras à chaîne courte: de la production colique aux effets physiologiques gastro-intestinaux (Short-chain fatty acids: from colonic production to physiological gastrointestinal effects). Sciences des Aliments 19, 269-290.

Brighenti F, Casiraghi MC \& Baggio C (1998) Starch in the Italian diet. British Journal of Nutrition 80, 333-341.

Brown IL, Wang X, Topping DL, Playne MJ \& Conway PL (1998) High amylose maize starch as a versatile prebiotic for use with probiotic bacteria. Food Australia 50, 603-622.

Burn J, Chapman PD, Bertario L, Bishop DT, Below S, Cummings J, Mathers J, Phillips R \& Vasen H (1995) The protocol for a European double-blind trial of aspirin and resistant starch in Familial Adenomatous Polyposis: The CAPP study. European Journal of Cancer 31A, 1385-1386.

Burn J, Chapman PD, Bishop DT \& Mathers J (1998) Diet and cancer prevention: The CAPP studies. Proceedings of the Nutrition Society 57, 183-186.

Cassidy A, Bingham SA \& Cummings JH (1994) Starch intake and colorectal cancer risk: an international comparison. British Journal of Cancer 69, 937-942.

Champ M (1992) Determination of resistant starch in foods and food products: interlaboratory study. European Journal of Clinical Nutrition 46, Suppl. 2, S51-S62.

Champ M, Kozlowski F \& Lecannu G (2001) In vivo and in vitro methods for resistant starch measurement. In Dietary Fibre, pp. 106-119 [BV McCleary and L Prosky, editors]. Oxford, UK: Blackwell Science.

Champ M, Martin L, Noah L \& Gratas M (1999a) Analytical methods for resistant starch. In Complex Carbohydrates in Foods, pp. 169-187 [SS Cho, L Prosky and M Dreher, editors]. New York, NY: Marcel Dekker Inc.

Champ M, Martin L, Noah L \& Gratas M (1999b) In vivo techniques to quantify resistant starch. In Complex Carbohydrates in Foods, pp. 157-167 [SS Cho, L Prosky and M Dreher, editors]. New York, NY: Marcel Dekker Inc.

Champ M, Molis C, Flourié B, Bornet F, Pellier P, Colonna P, Galmiche JP \& Rambaud JC (1998) Small intestinal digestion of partially resistant corn starch in healthy subjects. American Journal of Clinical Nutrition 68, 705-710.

Chapkin RS, Fan Y \& Lupton JR (2000) Effect of diet on colonicprogrammed cell death: molecular mechanism of action. Toxicology Letters 112-113, 411-414.

Cummings JH, Edwards C, Gee J, Nagengast F \& Mathers J (1994) Physiological effects of resistant starch in the large bowel. In Proceedings of the Concluding Plenary Meeting of EURESTA - Including the Final Reports of the Working Groups, pp. 38-55 [NG Asp, JMM van Amelsvoort and JGAJ Hautvast, editors]. Den Haag, The Netherlands: CIP-Data Koninklijke Bibliotheek.

Drasar BS \& Hill MJ (1974) Human Intestinal Flora. London: Academic Press.

Dysseler P \& Hoffem D (1994a) Estimation of resistant starch intake in Europe. In Proceedings of the Concluding Plenary Meeting of EURESTA, April 1994. European Flair-Concerted Action no. 11 (COST 911), pp. 84-86 [NG Asp, JMM van
Amelsvoort and JGAJ Hautvast, editors]. Den Haag, The Netherlands: CIP-Data Koninklijke Bibliotheek.

Dysseler P \& Hoffem D (1994b) Ring test for total and resistant starch determination. In Proceedings of the Concluding Plenary Meeting of EURESTA, April 1994. European Flair-Concerted Action no. 11 (COST 911), pp. 87-94 [NG Asp, JMM van Amelsvoort and JGAJ Hautvast, editors]. Den Haag, The Netherlands: CIP-Data Koninklijke Bibliotheek.

Englyst HN \& Cummings JH (1985) Digestion of the polysaccharides of some cereal foods in the human small intestine. American Journal of Clinical Nutrition 42, 778-787.

Englyst HN \& Cummings JH (1986) Digestion of the carbohydrates of banana (Musa paradisiaca sapientum) in the human small intestine. American Journal of Clinical Nutrition 44, 42-50.

Englyst HN \& Cummings JH (1987) Digestion of the polysaccharides of potato in the small intestine of man. American Journal of Clinical Nutrition 45, 423-431.

Englyst HN, Kingman SM \& Cummings JH (1992) Classification and measurement of nutritionally starch fractions. European Journal of Clinical Nutrition 46, Suppl. 2, S33-S50.

Englyst HN, Kingman SM, Hudson GJ \& Cummings JH (1996a) Measurement of resistant starch in vitro and in vivo. British Journal of Nutrition 75, 749-755.

Englyst HN, Quigley ME, Englyst KN, Bravo L \& Hudson GJ (1996b) Dietary fiber. Measurement by the Englyst NSP procedure. Measurement by the AOAC procedure. Explanation of the differences. Journal of the Association of Public Analysts 32, $1-52$.

Faisant N, Buléon A, Colonna P, Molis C, Lartigue S, Galmiche JP \& Champ M (1995a) Digestion of raw banana starch in the small intestine of healthy humans: structural features of resistant starch. British Journal of Nutrition 73, 111-123.

Faisant N, Champ M, Colonna P \& Buléon A (1993a) Structural discrepancies in resistant starch obtained in vivo in humans and in vitro. Carbohydrate Polymers 21, 205-209.

Faisant N, Champ M, Colonna P, Buléon A, Molis C, Langkilde AM, Schweizer T, Flourié B \& Galmiche JP (1993b) Structural features of resistant starch at the end of the human small intestine. European Journal of Clinical Nutrition 47, 285-296.

Faisant N, Champ M, Ranganathan SS, Azoulay C, Kergueris MF \& Krempf M (1994) Effects of resistant starch supplementation on postprandial metabolism in healthy subjects. In Proceedings of the Concluding Plenary Meeting of EURESTA, April 1994. European Flair-Concerted Action no. 11 (COST 911), pp. 113-114 [NG Asp, JMM van Amelsvoort and JGAJ Hautvast, editors]. Den Haag, The Netherlands: CIP-Data Koninklijke Bibliotheek.

Faisant N, Planchot V, Kozlowski F, Pacouret MP, Colonna P \& Champ M (1995b) Resistant starch determination adapted to products containing high level of resistant starch. Sciences des Aliments 15, 83-89.

Finegold SM, Sutter VL, Boyle JD \& Shimada K (1970) The normal flora of ileostomy and transverse colostomy effluents. Journal of Infectious Diseases 122, 376-381.

Flourié B, Florent C, Etanchaud F, Evard D, Franchisseur C \& Rambaud JC (1988) Starch absorption by healthy man evaluated by lactulose hydrogen breath test. American Journal of Clinical Nutrition 47, 61-66.

Flourié B, Florent C, Jouany JP, Thivend P, Eatanchaud F \& Rambaud JC (1986) Colonic metabolism of wheat starch in healthy humans. Effects on fecal outputs and clinical symptoms. Gastroenterology 90, 111-119.

Goñi I, Mañas E, Garcia-Diz L, Saura-Calixto F (1996) Analysis of resistant starch: a method for food and food products. Food Chemistry 56, 445-449.

Heijnen ML, Deurenberg P, van Amelsvoort JM \& Beynen AC (1997) Retrograded (RS3) but not uncooked (RS2) resistant 
starch lowers fecal ammonia concentrations in healthy men. American Journal of Clinical Nutrition 65, 167-169.

Heijnen MLA, van Amelsvoort JMM, Deurenberg P \& Beynen AC (1996) Neither raw nor retrograded resistant starch lowers fasting serum cholesterol concentrations in healthy normolipidemic subjects. American Journal of Clinical Nutrition 64, 312-318.

Heijnen MLA, van Amelsvoort JMM, Deurenberg P \& Beynen AC (1998) Limited effect of consumption of uncooked (RS2) or retrograded (RS3) resistant starch on putative risk factors for colon cancer in healthy men. American Journal of Clinical Nutrition 67, 322-331.

Hylla S, Gostner A, Dusel G, Anger H, Bartram HP, Christl SU, Kasper H \& Scheppach W (1998) Effects of resistant starch on the colon in healthy volunteers: possible implications for cancer prevention. American Journal of Clinical Nutrition 67, 136-142.

Kritchevsky D (1995) Epidemiology of fibre, resistant starch and colorectal cancer. European Journal of Cancer Prevention 4, 345-352.

Kruh J (1982) Effects of sodium butyrate, a new pharmacological agent, on cells in culture. Molecular and Cellular Biochemistry 42, 65-82.

Kruh J, Defer N \& Tichonicky L (1995) Effect of butyrate on cell proliferation and gene expression. In Physiological and Clinical Aspects of Short Chain Fatty Acids, pp. 278-288 [JH Cummings, JL Rombeau and T Sakata, editors]. Cambridge, UK: Cambridge University Press.

Langkilde AM \& Andersson H (1994) In vivo quantification of resistant starch in EURESTA reference materials using the ileostomy model. In Proceedings of the Concluding Plenary Meeting of EURESTA - Including the Final Reports of the Working Groups, pp. 31-32 [NG Asp, JMM van Amelsvoort and JGAJ Hautvast, editors]. Den Haag, The Netherlands: CIPData Koninklijke Bibliotheek.

Langkilde AM, Andersson H, Faisant N \& Champ M (1994) A comparison between the intubation technique and the ileostomy model for in vivo measurement of RS. In Proceedings of the Concluding Plenary Meeting of EURESTA - Including the Final Reports of the Working Groups, pp. 28-30 [NG Asp, JMM van Amelsvoort and JGAJ Hautvast, editors]. Den Haag, The Netherlands: CIP-Data Koninklijke Bibliotheek.

Langkilde AM, Champ M \& Andersson H (2002) Effects of highresistant-starch banana flour $(\mathrm{RS}(2))$ on in vitro fermentation and the small-bowell excretion of energy, nutrients, and sterols: an ileostomy study. American Journal of Clinical Nutriton $\mathbf{7 5}$, 104-111.

Langkilde AM, Ekwall H, Bjorck I, Asp NG \& Andersson H (1998) Retrograded high-amylose corn starch reduces cholic acid excretion from the small bowel in ileostomy subjects. European Journal of Clinical Nutrition 52, 790-795.

Lee SC, Prosky L \& De Vries JW (1992) Determination of total, soluble, and insoluble dietary fiber in foods - enzymatic-gravimetric method, MES-TRIS buffer: collaborative study. Journal of AOAC International 71, 395-416.

Levitt MD (1969) Production and excretion of hydrogen gas in man. New England Journal of Medicine 284, 1394-1398.

Lia A, Sundberg B, Aman P, Sandberg AS, Hallmans G \& Andersson H (1996) Substrates available for colonic fermentation from oat, barley and wheat bread diets. A study in ileostomy subjects. British Journal of Nutrition 76, 797-808.

Livesey G (1994) Energy value of resistant starch. In Proceedings of the Concluding Plenary Meeting of EURESTA, April 1994. European Flair-Concerted Action no. 11 (COST 911), pp. 56-62 [NG Asp, JMM van Amelsvoort and JGAJ Hautvast, editors]. Den Haag, The Netherlands: CIP-Data Koninklijke Bibliotheek.

Livesey G, Wilkinson JA, Roe M, Faulks R, Clark S, Brown JC, Kennedy H \& Elia M (1995) Influence of the physical form of barley grain on the digestion of its starch in the human small intestine and implications for health. American Journal of Clinical Nutrition 61, 75-81.

McCleary BV, McNally M \& Rossiter P (2002a) Measurement of resistant starch by enzymatic digestion in starch and selected plant materials: collaborative study. Journal of AOAC International 85, 1103-1111.

McCleary BV \& Monaghan DA (2002) Measurement of resistant starch. Journal of AOAC International 85, 665-675.

McIntyre A, Gibson PR \& Young GP (1993) Butyrate production from dietary fibre and protection against large bowel cancer in a rat model. Gut 34, 386-391.

Martin LJ, Dumon HJ, Lecannu G \& Champ MM (2000) Potato and high-amylose maize starches are not equivalent producers of butyrate for the colonic mucosa. British Journal of Nutrition 84, 689-696.

Muir JG, Birkett A, Brown, I, Jones G \& O’Dea K (1995) Food processing and maize variety affects amounts of starch escaping digestion in the small intestine. American Journal of Clinical Nutrition 61, 82-89.

Muir JG \& O'Dea K (1992) Measurement of resistant starch: factors affecting the amount of starch escaping digestion in vitro. American Journal of Clinical Nutrition 56, 123-127.

Muir JG \& O'Dea K (1993) Validation of an in vitro assay for predicting the amount of starch that escapes digestion in the small intestine of humans. American Journal of Clinical Nutrition 57, $540-546$.

Noah L, Guillon F, Bouchet B, Buléon A, Molis C, Gratas M \& Champ M (1998) Digestion of carbohydrate from home cooked white beans (Phaseolus vulgaris L.) in healthy humans. Journal of Nutrition 128, 977-985.

Perrin P, Pierre F, Patry Y, Champ M, Berreur M, Pradal G, Bornet F, Meflah K \& Menanteau J (2001) Only fibres promoting a stable butyrate producing colonic ecosystem decrease the rate of aberrant crypt foci in rats. Gut 48, 53-61.

Phillips J, Muir JG, Birkett A, Lu ZX, Jones GP, O'Dea K \& Young GP (1995) Effect of resistant starch on fecal bulk and fermentation-dependent events in humans. American Journal of Clinical Nutrition 62, 121-130.

Pierre F, Perrin P, Champ M, Bornet F, Méflah K \& Ménanteau J (1997) Short-Chain Fructo-oligosaccharides reduce the occurrence of colon tumors and development of gut-associated lymphoid tissue in Min Mice. Cancer Research 57, 225-228.

Planchot V, Colonna P \& Buleon A (1997) Enzymatic hydrolysis of $\alpha$-glucan crystallites. Carbohydrate Research 298, 319-326.

Prosky L, Asp NG, Furda I, Devries JW, Schweizer TF \& Harland BF (1984) Determination of total dietary fiber in foods and food products and total diets: collaborative study. Journal of the Association of Official Analytical Chemists 67, 1044-1053.

Prosky L, Asp NG, Schweizer TF, DeVries JW \& Furda I (1988) Determination of insoluble, soluble, and total dietary fiber in foods and food products: interlaboratory study. Journal of the Association of Official Analytical Chemists 71, 1017-1023.

Prosky L, Asp NG, Furda I, DeVries JW, Schweizer TF \& Harland BF (1985) Determination of total dietary fiber in foods and food products: collaborative study. Journal of the Association of Official Analytical Chemists 68, 677-679.

Raben A, Tagliabue A, Christensen NJ, Madsen J, Holst JJ \& Astrup A (1994) Resistant starch: the effect on postprandial glycemia, hormonal response, and satiety. American Journal of Clinical Nutrition 60, 544-551.

Ranganathan S, Champ M, Pechard C, Blanchard P, N'Guyen M, Colonna P \& Krempf M (1994) Comparative study of the acute effects of resistant starch and dietary fibers on metabolic indexes in man. American Journal of Clinical Nutrition 59, 879-883.

Rowland IR, Rumney CJ, Coutts JT \& Lievense LC (1998) Effect of Bifidobacterium longum and inulin on gut bacterial metabo- 
lism and carcinogen-induced aberrant crypt foci in rats. Carcinogenesis 19, 281-285.

Rumessen JJ (1992) Hydrogen and methane breath tests for evaluation of resistant carbohydrates. European Journal of Clinical Nutrition 46, Suppl. 2, S77-S90.

Sakamoto J, Nakaji S, Sugawara K, Iwane S \& Munakata A (1996) Comparison of resistant starch with cellulose diet on 1,2-dimethylhydrazine-induced colonic carcinogenesis in rats. Gastroenterology 110, 116-120.

Sandberg AS, Andersson H, Hallgren B, Hasselblad K, Isaksson B \& Hulten L (1981) Experimental model for in vivo determination of dietary fibre and its effect on the absorption of nutrients in the small intestine. British Journal of Nutrition 45, 283-294.

Sandberg AS, Andersson H, Kivisto B \& Sandstrom B (1983) Extrusion cooking of a high-fibre cereal product. 1. Effects on digestibility and absorption of protein, fat, starch, dietary fibre and phytate in the small intestine. British Journal of Nutrition 55, 245-254.

Scheppach W, Fabian C, Sachs M \& Kasper H (1988) The effect of starch malabsorption on fecal short chain fatty acid excretion in man. Scandinavian Journal of Gastroenterology 23, 755-759.

Schweizer TF, Walter E \& Venetz P (1988) Collaborative study for the enzymatic, gravimetric determination of total dietary fibre in foods. Mitteilungen aus der Gebiete der Lebensmitteluntersuchung und Hygiene 79, 57-68.

Shetty PS \& Kurpach AV (1986) Increased starch intake in the human diet increases fecal bulking. American Journal of Clinical Nutrition 43, 210-212.
Stephen AM, Haddad AC \& Phillips SF (1983) Passage of carbohydrate into the colon. Direct measurements in humans. Gastroenterology 85, 589-595.

Stephen AM, Sieber GM, Gerster YA \& Morgan DR (1995) Intake of carbohydrate and its components - international comparisons, trends over time, and effects of changing to lowfat diets. American Journal of Clinical Nutrition 62, 851S-867S.

Thorup I, Meyer O \& Kristiansen E (1995) Effect of potato starch, corn starch and sucrose on aberrant crypt foci in rats exposed to azoxymethane. Anticancer Research 15B, 2101-2105.

Tomlin J \& Read NW (1990) The effect of resistant starch on colon function in humans. British Journal of Nutrition 64, $589-595$.

Van Munster IP, Tangerman A \& Nagengast FM (1994) Effect of resistant starch on colonic fermentation, bile acid metabolism and mucosal proliferation. Digestive Diseases Science 39 834-842.

Whitehead RH, Young GP \& Bhathal PS (1986) Effects of short chain fatty acids on a new human carcinoma cell line (LIM1215). Gut 27, 1427-1463.

Würsch P \& Koellreuter B (1992) Susceptibility of resistant starch to $\alpha$-amylase. European Journal of Clinical Nutrition $\mathbf{4 6}$, Suppl. 2, S113-S115.

Young GP, McIntyre A, Albert V, Folino M, Muir JG \& Gibson PR (1996) Wheat bran suppresses potato starch-potentiated colorectal tumorigenesis at the aberrant crypt stage in a rat model. Gastroenterology 110, 508-514. 
https://doi.org/10.1079/NRR200364 Published online by Cambridge University Press 